J Am Chem Soc. 2019 July 03; 141(26): 10462-10474. doi:10.1021/jacs.9b04699.

\title{
Operando Spectroscopic and Kinetic Characterization of Aerobic Allylic C-H Acetoxylation Catalyzed by $\mathrm{Pd}(\mathrm{OAc})_{2} / 4,5-$ Diazafluoren-9-one
}

\author{
Jonathan N. Jaworski ${ }^{\dagger}$, Caitlin V. Kozack ${ }^{\dagger}$, Stephen J. Tereniak ${ }^{\dagger}$, Spring Melody M. Knapp ${ }^{\dagger}$, \\ Clark R. Landis ${ }^{\dagger}$, Jeffrey T. Miller ${ }^{\ddagger}$, Shannon S. Stahl ${ }^{\star}, \dagger$ \\ † Department of Chemistry, University of Wisconsin-Madison, 1101 University Avenue Madison, \\ WI, 53706, United States \\ ‡ David School of Chemical Engineering, Purdue University, 480 Stadium Mall Dr., West \\ Lafayette, IN 47907, United States
}

\begin{abstract}
Allylic $\mathrm{C}-\mathrm{H}$ acetoxylations are among the most widely studied palladium(II)-catalyzed $\mathrm{C}-\mathrm{H}$ oxidation reactions. While the principal reaction steps are well established, key features of the catalytic mechanisms are poorly characterized, including the identity of the turnover-limiting step and the catalyst resting state. Here, we report a mechanistic study of aerobic allylic acetoxylation of allylbenzene with a catalyst system composed of $\mathrm{Pd}(\mathrm{OAc})_{2}$ and 4,5-diazafluoren-9-one (DAF). The DAF ligand is unique in its ability to support aerobic catalytic turnover, even in the absence of benzoquinone or other co-catalysts. Herein, we describe operando spectroscopic analysis of the catalytic reaction using X-ray absorption and NMR spectroscopic methods that allow direct observation of the formation and decay of a palladium(I) species during the reaction. Kinetic studies reveal the presence of two distinct kinetic phases: (1) a burst phase, involving rapid formation of the allylic acetoxylation product and formation of the dimeric $\mathrm{Pd}^{\mathrm{I}}$ complex $\left[\mathrm{Pd}^{\mathrm{I}}(\mathrm{DAF})(\mathrm{OAc})\right]_{2}$, followed by (2) a post-burst phase that coincides with evolution of the catalyst resting state from the $\mathrm{Pd}^{\mathrm{I}}$ dimer into a $\pi$-allyl-Pd ${ }^{\mathrm{II}}$ species. The data provide unprecedented insights into the role of ancillary ligands in supporting catalytic turnover with $\mathrm{O}_{2}$ as the stoichiometric oxidant and establish an important foundation for the development of improved catalysts for allylic oxidation reactions.
\end{abstract}

\section{Graphical Abstract}

\footnotetext{
*Corresponding Author: stahl@chem.wisc.edu.

The authors declare no competing financial interests.

ASSOCIATED CONTENT

Supporting Information. The Supporting Information is available free of charge on the ACS Publications website: Experimental details and compound characterization data (PDF); Crystallographic data for 3 and $\mathbf{4}$ (CIF).
} 

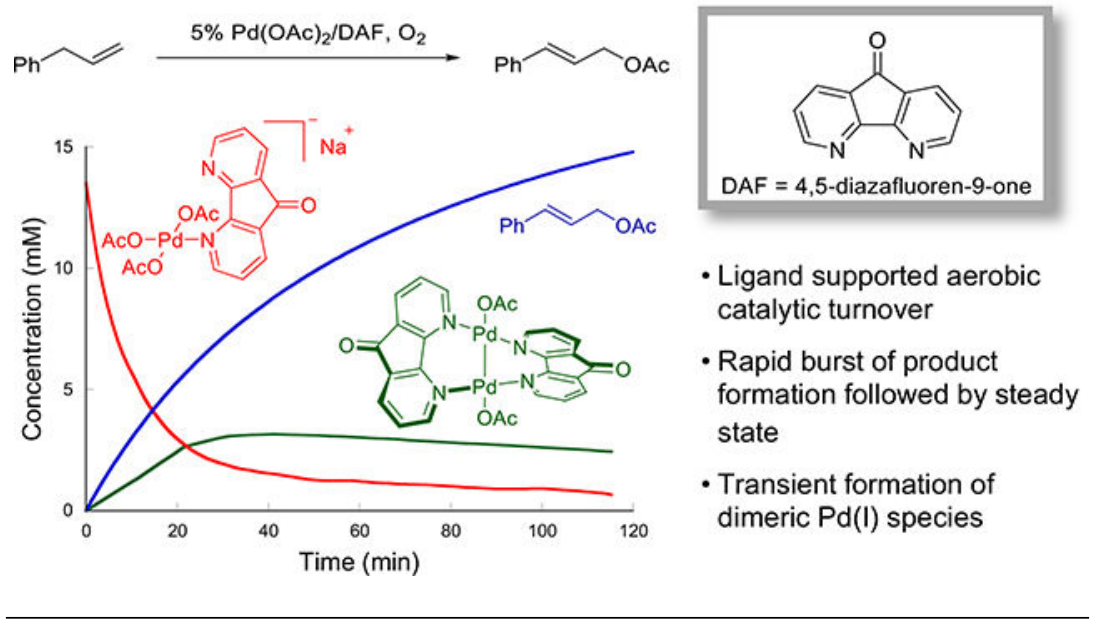

\section{Introduction}

The Wacker process for industrial production of acetaldehyde from ethylene was discovered in $1959,{ }^{1}$ and three years later Vargaftik et al. reported the first example of $\mathrm{Pd}^{\mathrm{II}}$-mediated allylic acetoxylation of olefins. ${ }^{2}$ The latter reaction employed stoichiometric $\mathrm{PdCl}_{2}$ in acetic acid and generated linear allyl acetates from terminal olefins, such as 1-hexene. Shortly thereafter, Anderson and Winstein reported allylic acetoxylation of cyclohexene with stoichiometric $\mathrm{Pd}(\mathrm{OAc})_{2} \cdot{ }^{3}$ In the subsequent half century, extensive efforts were directed toward the development of catalytic methods for this reaction through the combination of $\mathrm{Pd}^{\mathrm{II}}$ sources with a stoichiometric oxidant capable of promoting reoxidation of $\mathrm{Pd}^{0}$ to $\mathrm{Pd}^{\mathrm{II}}{ }^{4}$ The most widely used oxidant is benzoquinone, ${ }^{2-13}$ but other oxidants include $\mathrm{CuCl}_{2},{ }^{14,15}$ inorganic and organic peroxides, ${ }^{16-19}$ and hypervalent iodine reagents. ${ }^{20,21}$ Molecular oxygen is also a viable oxidant, typically when used in combination with one or more redox active cocatalysts to facilitate regeneration of the $\mathrm{Pd}^{\mathrm{II}}$ catalyst. ${ }^{22-30}$

The development of ligand-supported catalyst systems has stimulated renewed interest in Pd-catalyzed allylic oxidation reactions in recent years. ${ }^{7,8,12,31}$ These catalyst systems, which contrast the simple $\mathrm{Pd}^{\mathrm{II}}$ salts [e.g., $\mathrm{PdCl}_{2}$ or $\mathrm{Pd}(\mathrm{OAc})_{2}$ ] primarily employed as catalysts during the first four decades of the field, facilitate catalyst optimization efforts and introduce new opportunities to achieve catalyst controlled selectivity in the reactions. For example, chelating ligands bearing one or two sulfoxides have been used in reactions that generate branched allyl acetates from terminal olefins, ${ }^{7,12}$ rather than the more commonly observed linear allyl acetates. This ligand-controlled regioselectivity has been implemented in a number of synthetic applications, ${ }^{32-34}$ and other ligand-supported catalysts have begun showing promise in enantioselective and diastereoselective reactions. ${ }^{9,35-38}$ Ligands can also support more efficient catalysis, ${ }^{39-41}$ as revealed by the ability of 4,5-diazafluoren-9one (DAF) to support aerobic catalytic turnover, even in the absence of redoxactive cocatalysts. ${ }^{31}$

In spite of the long history and recent progress, Pd-catalyzed allylic oxidation reactions remain at a relatively early stage of development in comparison to other Pd-catalyzed reactions, with none of the existing catalyst systems exhibiting a full complement of 
desirable characteristics. For example, catalyst systems that support aerobic catalytic turnover generate only linear allyl acetate products with terminal olefins, ${ }^{30,31}$ while catalyst systems that enable branched product formation exhibit relatively poor catalytic performance (e.g., 3-10 turnovers, 48-72 $\mathrm{h}$ reaction times) and are not effective with $\mathrm{O}_{2}$ as the oxidant. ${ }^{8,12}$ The mechanistic origin of these limitations is poorly understood. While the basic reaction steps associated with $\mathrm{Pd}$-catalyzed allylic $\mathrm{C}-\mathrm{H}$ oxidation are well established, few insights are available into the catalytic mechanisms, such as the identity of the turnover limiting step, the composition of the catalyst resting state, and the influence of ancillary ligands on these features. Insights of this type have played a major role in advancing other classes of homogeneous catalytic reactions. For example, Pd-catalyzed cross-coupling methods are some of the most versatile methods in synthetic chemistry. The basic reaction steps involved in these reactions were well established by the early 1970s, but the development of more efficient catalysts, expansion of the synthetic scope and utility, and the emergence of new reaction classes (e.g., Buchwald-Hartwig reactions) in subsequent decades benefitted greatly from mechanistic studies of catalytic reactions. ${ }^{42-45}$ For example, insights into the kinetic bottlenecks of the catalytic cycle and characterization of the catalyst species, including on- and off-cycle species, ${ }^{46-48}$ provided a foundation for the discovery of new ligands, ${ }^{49-51}$ catalyst systems, ${ }^{52}$ and reaction conditions that overcame existing limitations. ${ }^{53,54}$ The iterative synergy between empirical and mechanistic studies is much less evident in the field of Pd-catalyzed allylic oxidation reactions; however, the emergence of ligand-supported catalyst systems amenable to this approach is still relatively recent.

Here, we report the first kinetic and mechanistic investigation of a Pd-catalyzed method for aerobic allylic $\mathrm{C}-\mathrm{H}$ oxidation, focusing on $\mathrm{DAF} / \mathrm{Pd}(\mathrm{OAc})_{2}$-catalyzed acetoxylation of allylbenzene, for which the basic steps are illustrated in Scheme 1. The initial report of this catalyst revealed that DAF is unique in its ability to support aerobic catalytic turnover among a series of (bi)pyridyl-based ligands (Scheme 2), ${ }^{31,55,56}$ and investigation of stoichiometric reactions with $\pi$-allyl-Pd ${ }^{\mathrm{II}}$ species showed that DAF promotes reductive elimination ${ }^{57}$ of the allyl acetate product. ${ }^{31,58}$ The implications of these observations were not extended to catalytic conditions, however, and the present study provides a comprehensive analysis of the catalytic mechanism, including kinetic studies and operando X-ray absorption spectroscopy (XAS) and NMR spectroscopic analysis of the catalytic reaction, which reveal changes in the identity of the turnover limiting step and evolution of the catalyst species during the reaction. The results provide valuable insights into Pdcatalyzed allylic oxidation reactions and the ability of DAF to support aerobic catalytic turnover, ${ }^{59-69}$ and this study establishes an important foundation for future empirical and mechanistic efforts directed toward the identification of more efficient and synthetically useful allylic $\mathrm{C}-\mathrm{H}$ oxidation catalyst systems.

\section{Results and Discussion}

\section{Initial mechanistic observations}

In a recent study, we showed that $\mathrm{DAF} / \mathrm{Pd}(\mathrm{OAc})_{2}$-catalyzed allylic acetoxylation of allylbenzene exhibits a kinetic burst at the beginning of the reaction and generates a dimeric $\mathrm{Pd}^{\mathrm{I}}$ species under the catalytic conditions. ${ }^{70}$ These preliminary results, reproduced in Figure 
1, provided a starting point for the present investigation, with the goal of understanding the origin and implications of these observations. The burst is accompanied by a change in the color of the reaction solution from yellow to red, but, as the reaction progresses past the burst, the reaction solution changes color again from red to yellow. The latter color persists for the remainder of the reaction. ${ }^{71} \mathrm{~A}$ red $\mathrm{Pd}^{\mathrm{I}}$ dimer, $\left[\mathrm{Pd}{ }^{\mathrm{I}}(\mathrm{DAF})(\mathrm{OAc})\right]_{2} \mathbf{2}$, was independently synthesized and characterized by X-ray crystallography (Figure 1B), and it exhibits a UV-visible absorption spectrum that closely matches the UV-vis spectra observed from the catalytic reaction mixture (Figure 1C). ${ }^{70}$

\section{Interrogation of the catalyst speciation by X-ray absorption spectroscopy}

The data noted above imply that the oxidation state of the Pd catalyst changes during the course of the reaction. Palladium K-edge X-ray absorption spectroscopy probes the excitation of Pd 1s electrons, and the "near edge" absorption energy, corresponding to the $1 \mathrm{~s}$ $\rightarrow 5 \mathrm{p}$ orbital transition, provides insight into the oxidation state of Pd complexes. ${ }^{72,73}$ This technique has been used to probe a number of homogeneous Pd-catalyzed reactions, ${ }^{74-79}$ including recent analysis of a Pd-catalyzed aerobic oxidation of an aromatic $\mathrm{C}-\mathrm{H}$ bond ${ }^{80} \mathrm{In}$ order to conduct analogous experiments for the allylic acetoxylation reaction, a reactor was designed and constructed to enable operando studies on the high photon-flux beamline at Argonne National Laboratories (see Supporting Information for details; Figures S3-S6).

Pd K-edge XANES spectra were obtained for a series of $\mathrm{Pd}^{0}, \mathrm{Pd}^{\mathrm{I}}$, and $\mathrm{Pd}^{\mathrm{II}}$ reference compounds: $\mathrm{Pd}^{0}\left(\mathrm{Pd}_{2}(\mathrm{dba})_{3}\right), \mathrm{Pd}^{\mathrm{I}}\left(\left[\mathrm{Pd}^{\mathrm{I}}(\mathrm{DAF})(\mathrm{OAc})\right]_{2}(\mathbf{2})\right)$, and $\mathrm{Pd}^{\mathrm{II}}\left(1: 1 \mathrm{DAF} / \mathrm{Pd}(\mathrm{OAc})_{2}(\mathbf{1})\right.$; $\left[\mathrm{Pd}^{\mathrm{II}}(\pi \text {-cinnamyl })(\mathrm{OAc})\right]_{2}(\mathbf{3})$; and $\left[\mathrm{Pd}^{\mathrm{II}}(\mathrm{DAF})(\pi\right.$-cinnamyl $\left.\left.)\right] \mathrm{BF}_{4}(\mathbf{4})\right)$. Similar spectra were then acquired during the course of the catalytic reaction, ${ }^{81}$ with a time course of the edge energy shown together with selected reference compounds in Figure 2A. Upon initiation of the reaction by injecting allylbenzene, the edge energy shifts rapidly from its initial position associated with 1 to a lower energy position, consistent with reduction of the catalyst during the burst (spectrum $\mathbf{B}$ ). The new edge energy is very similar to that of the $\mathrm{Pd}^{\mathrm{I}}$ dimer reference (cf. 2, Figure 2B). Analysis of the extended X-ray absorption fine-structure (EXAFS) region of the spectra revealed three prominent scattering peaks during the first 13 min of the reaction, and these peaks are very similar to those observed with an authentic sample of the Pd ${ }^{\mathrm{I}}$ dimer 2 (Figure 3A). Collectively, the XANES and EXAFS spectra support the formation of $\mathrm{Pd}^{\mathrm{I}}$ species $\mathbf{2}$ as a catalytic intermediate during the burst phase of the reaction.

As the reaction proceeds, the edge increases gradually to higher energy, ultimately reaching an energy intermediate between that of $\mathrm{DAF} / \mathrm{Pd}^{\mathrm{II}}(\mathrm{OAc})_{2} \mathbf{1}$ and the $\mathrm{Pd}^{\mathrm{I}}$ dimer 2 (Figure $2 \mathrm{~A}$ ). An isosbestic point is evident in the XANES spectra during this phase of the reaction (cf. Figure 2A), suggesting that the $\mathrm{Pd}^{\mathrm{I}}$ dimer converts directly into a new Pd species, which has a higher formal oxidation state. The XANES spectrum for the catalyst resting state in the post-burst phase $(\mathbf{P B})$ is clearly different from the $\mathrm{DAF} / \mathrm{Pd}^{\mathrm{II}}(\mathrm{OAc})_{2}$ pre-catalyst $\mathbf{1}$, and it closely resembles the spectra of the independently prepared $\pi$-allyl-Pd ${ }^{\mathrm{II}}$ species, the dimeric species $\left[\mathrm{Pd}^{\mathrm{II}}(\pi \text {-cinnamyl })(\mathrm{OAc})\right]_{2}(\mathbf{3})$ and the monomeric DAF-ligated $\pi$-allyl-Pd ${ }^{\mathrm{II}}$ species, $\left[\mathrm{Pd}^{\mathrm{II}}(\mathrm{DAF})(\pi\right.$-cinnamyl) $] \mathrm{BF}_{4}(4)$ (Figure $\left.2 \mathrm{C}\right)$. The changes evident in the XANES spectra were also evident in a comparison of the inflection point in the spectra for the Pd species 
present during the reaction relative to the approximate edge energies of the $\mathrm{Pd}^{\mathrm{I}}$ and $\mathrm{Pd}^{\mathrm{II}}$ reference compounds (Figure 4). Analysis of the EXAFS spectral region during the postburst portion of the reaction also reveal similarities between the post-burst $\mathrm{Pd}^{\mathrm{II}}$ intermediate (PB) and the $\pi$-allyl-Pd ${ }^{\mathrm{II}}$ reference compounds (Figure 3B).

\section{Interrogation of catalyst speciation by NMR spectroscopy}

The catalyst speciation during the reaction time course was also interrogated by NMR spectroscopic methods. The reaction employs a mixture of $\mathrm{AcOH} / \mathrm{NaOAc}$ as the solvent and source of acetate nucleophile, and the predominant palladium species observed by ${ }^{1} \mathrm{H}$ NMR spectroscopy at the start of the reaction was identified as an "ate" complex, $\mathrm{Na}\left[\left(\kappa^{1}-\right.\right.$ DAF)Pd $\left.{ }^{\mathrm{II}}(\mathrm{OAc})_{3}\right]$ (5). This assignment was supported by NMR integrations and independent titration studies involving addition of NaOAc to a solution of DAF and $\mathrm{Pd}^{\mathrm{II}}(\mathrm{OAc})_{2}$ (Figures S20-S24). A time course of the reaction was monitored by ${ }^{1} \mathrm{H}$ NMR spectroscopy by using a sealed NMR tube pressurized with $3.2 \mathrm{~atm}$ of static $\mathrm{O}_{2}$. The data reveal rapid product formation with concurrent conversion of the $\mathrm{Pd}^{\mathrm{II}}$ ate complex 5 into the $\mathrm{Pd}^{\mathrm{I}}$ dimer 2 (Figure 5). The concentration of $\mathrm{Pd}^{\mathrm{I}}$ maximizes at the end of the kinetic burst of product formation ( $t$ $\sim 20 \mathrm{~min}$ ), after which the rate of cinnamyl acetate product formation decreases to a steadystate rate. Unligated DAF becomes evident in the reaction mixture and its concentration increases during the steady state reaction period (Figure 5 - expansion).

To investigate the catalyst speciation at early reaction times (i.e., during the burst period), thick-walled NMR tubes were prepared with different pressures of $\mathrm{O}_{2} \cdot{ }^{82-84}$ Plots showing the formation of cinnamyl acetate and the $\mathrm{Pd}^{\mathrm{I}} \operatorname{dimer}(2)$ at $0.2-6.2$ atm $\mathrm{O}_{2}$ are provided in Figure 6. Nearly identical rates of product formation (i.e., independent of the $p \mathrm{O}_{2}$ ) are evident during the burst phase; however, the rate of product formation after the burst phase increases with increasing $p \mathrm{O}_{2}$ (Figure 6A). Complementary analysis of the Pd species shows that the amount of $\mathrm{Pd}^{\mathrm{I}}$ dimer $\mathbf{2}$ generated during the burst phase decreases with increasing $p \mathrm{O}_{2}$ (Figure 6B; see Supporting Information for further details).

To complement these data, the recently developed Wisconsin High Pressure NMR Reactor (WiHP-NMRR) $)^{85-87}$ was used to monitor the dependence of the rate on $\mathrm{O}_{2}$ pressure $\left(p \mathrm{O}_{2}\right)$. This apparatus provides continuous gas circulation in the liquid during the NMR relaxation delay (d1). This dynamic gas supply allows for better control of dissolved $\mathrm{O}_{2}$ concentration during the reaction and avoiding complications that can arise from the lack of gas-liquid mixing in an NMR tube when a static pressure of $\mathrm{O}_{2}$ is used. ${ }^{88}$ Consistent with the data in Figure 6, the rate of product formation during the burst phase was not affected by changes in $p \mathrm{O}_{2}$, while a saturation dependence of the rate on $p \mathrm{O}_{2}$ was evident from kinetic data after the burst (Figure 7).

Another set of studies was conducted to probe the influence of substrate concentration on the reaction rate and Pd speciation during the early periods of the reaction $(0.135-1.08 \mathrm{M}$ allylbenzene). The overall rate of product formation increased with higher [allylbenzene] (Figure 8A). An increase in the rates of formation and decay of the $\mathrm{Pd}^{\mathrm{I}}$ dimer 2 with increasing [allylbenzene] results in a similar maximum concentration of $\mathbf{2}$ under all conditions, but a shorter lifetime for this species at higher substrate concentration (Figure $8 B)$. 


\section{Kinetic studies and isotope effects}

More thorough kinetic studies were performed to probe the contributions of each of the reaction components to the reaction rate during the burst and post-burst phases of the reaction (Figures 9 and 10). These studies were conducted at $40^{\circ} \mathrm{C}$ and $80^{\circ} \mathrm{C}$, respectively, by removing aliquots of the reaction mixture and analyzing product formation by gas chromatography (GC). Analysis of the burst phase was carried out at lower temperature to enable acquisition of more precise data, but the results are consistent with general trends observed at higher temperatures. A linear dependence of the rate on the 1:1 DAF/Pd ${ }^{\mathrm{II}}(\mathrm{OAc})_{2}$ catalyst concentration [1] was observed during the burst phase, while a slight saturation dependence was evident in the post-burst regime (Figures 9A and 10A, respectively). In both the burst and post-burst phases, the rate exhibits a nearly linear dependence on [DAF] up to a 1:1 DAF/Pd ${ }^{\mathrm{II}}(\mathrm{OAc})_{2}$ ratio; however, increasing [DAF] beyond a 1:1 ratio decreases the rate of the burst, while it does not affect the rate during post-burst turnover (Figures $9 \mathrm{~B}$ and 10B). A nearly linear dependence on [allylbenzene] was observed in the burst and post-burst phases (Figures 9C and 10C), but the data intersect at the origin for the burst kinetics, while the post-burst kinetic data exhibit a substantial non-zero intercept. The positive order in [allylbenzene] in both cases correlates with the kinetic influence of allylbenzene on the rate of formation and decay of the $\mathrm{Pd}^{\mathrm{I}}$ dimer $\mathbf{2}$ observed in the NMR spectroscopic studies shown in Figure 8B.

Two deuterium-labeled substrates were synthesized to probe intramolecular and intermolecular kinetic isotope effects (KIEs). 4-Allylbiphenyl (6) was selected as the substrate for these studies because it is not volatile and is easier to purify than the parent allylbenzene. ${ }^{89}$ Independent rates were measured with 6 and $6-d_{2}$ substrates, and intramolecular competition KIEs with 6- $d_{1}$ were determined via ${ }^{1} \mathrm{H}$ NMR spectroscopy by quantifying the product formation derived from $\mathrm{C}-\mathrm{H}$ or $\mathrm{C}-\mathrm{D}$ activation. The primary KIEs evident in the burst phase from both sets of experiments (Table 1, entries 1 and 2) are rather small, but very similar to that observed in a recent allylic amination reaction..${ }^{90}$ In the period of the reaction after the burst, the intramolecular competition experiment revealed a KIE similar to that observed in the burst phase (cf. entry 3 vs entries 1 and 2), but essentially no KIE was observed from the independent rate measurements (entry 4).

\section{Evolution of a $\pi$-cinnamyl-Pd" resting state following the burst}

The XAS data described above implicate the possibility of a $\pi$-allyl-Pd ${ }^{\mathrm{II}}$ species as the catalyst resting state during the post-burst phase of the reaction. Initial attempts to observe such a species directly by ${ }^{1} \mathrm{H}$ NMR spectroscopy were unsuccessful, however, possibly reflecting a high degree of fluxionality associated with such a species. ${ }^{91-93}$ The NMR time course in Figure 5 suggests that the DAF ligand dissociates from the Pd center during the reaction, a feature that could further contribute to the fluxionality of a $\pi$-allyl-Pd ${ }^{\mathrm{II}}$ species and complicate its detection by ${ }^{1} \mathrm{H}$ NMR spectroscopy.

To overcome this complication, we analyzed the catalytic acetoxylation of 4fluoroallylbenzene to probe the reaction by ${ }^{19} \mathrm{~F}$ NMR spectroscopy. Operando analysis of the catalytic reaction was conducted throughout the time course using the WiHP-NMRR in an effort to identify possible intermediates. During the burst phase, ${ }^{19} \mathrm{~F}$ NMR resonances are 
evident only for the alkene starting material (-113.4 ppm) and cinnamyl acetate product $(-110 \mathrm{ppm})$ (e.g., Figure 11a). As the reaction proceeds, however, a new resonance becomes evident at $-109.2 \mathrm{ppm}$. (Figure 11b; see Figure S12 for additional spectra). The chemical shift of this peak, denoted $\mathbf{I}$, is very similar that observed from an independently prepared sample of the 4-fluorophenyl derivative of the $\pi$-cinnamyl-Pd ${ }^{\mathrm{II}}$ dimer 3 (i.e., $\mathbf{3}^{\mathrm{F}}$ ) and the same compound in the presence of DAF (DAF:Pd = 1:1) (Figures 11c and 11d). Integration of this resonance during the course of the catalytic reaction show that this species accounts for nearly all of the Pd catalyst present in solution (Figure 12), thereby providing direct support for evolution of the catalyst into a $\pi$-allyl-Pd ${ }^{\mathrm{II}}$ resting state following the burst.

In light of these observations, the initial time course of the catalytic acetoxylation of allylbenzene was analyzed by comparing reactions conducted with $\mathrm{Pd}(\mathrm{OAc})_{2}$ and $\left[\mathrm{Pd}^{\mathrm{II}}(\pi-\right.$ cinnamyl $(\mathrm{OAc})]_{2}(\mathbf{3})$ as the source of Pd catalyst, under otherwise identical conditions. The data in Figure 13 show that no burst is observed when $\mathbf{3}$ is used as the Pd precatalyst, and the initial rate in this reaction resembles that of the post-burst rate observed from the reaction initiated with $\mathrm{Pd}(\mathrm{OAc})_{2}$ as the precatalyst.

\section{Investigation of allyl acetate reductive elimination from [Pd" $(\pi-c i n n a m y l)(O A c)]_{2}$}

Identification of a $\pi$-allyl-Pd ${ }^{\mathrm{II}}$ resting state during the catalytic reaction prompted us to prepare the well-defined $\left[\mathrm{Pd}^{\mathrm{II}}(\pi \text {-cinnamyl })(\mathrm{OAc})\right]_{2}$ species 3 to explore its reactivity under catalytically relevant conditions (Figure 14). As a control experiment, negligible reductive elimination of cinnamyl acetate ${ }^{57}$ was observed under $\mathrm{N}_{2}$ in the absence of the DAF ligand (Figure 14, condition a). Some reactivity was observed upon addition of DAF to the solution of 3 under $\mathrm{N}_{2}$ (condition $b$ ), consistent with previously reported observations, ${ }^{31}$ and further enhancement of the reaction was observed upon adding an equivalent of DAF/Pd ${ }^{\mathrm{II}}(\mathrm{OAc})_{2}$ (condition $c$ ). The latter conditions led to significant formation of the $\mathrm{Pd}^{\mathrm{I}}$ dimer $\mathbf{2}$. These reactions were also enhanced by conducting the reaction under an atmosphere of $\mathrm{O}_{2}$ (conditions $d$ and $e$ ). The last of these conditions (e) resemble the reaction conditions present during the burst phase of the catalytic reaction, when allylic $\mathrm{C}-\mathrm{H}$ activation and formation of an allyl-Pd ${ }^{\mathrm{II}}$ intermediate will take place in the presence of additional $\mathrm{DAF} / \mathrm{Pd}^{\mathrm{II}}(\mathrm{OAc})_{2}$ precatalyst, which can react with the $\mathrm{Pd}^{0}$ species formed upon reductive elimination of cinnamyl acetate and generate the $\mathrm{Pd}^{\mathrm{I}}$ dimer $\mathbf{2}$ (see further discussion below). The presence of allylbenzene has negligible effect on the rate of reductive elimination (see Figure S17 in the Supporting Information), suggesting that the beneficial kinetic effect of allylbenzene after the burst (cf. Figure 10C) does not arise from the reductive elimination step, but rather from its contribution to catalyst speciation (i.e., by promoting conversion of $\mathrm{Pd}^{\mathrm{I}}$ dimer $\mathbf{2}$ into the steady-state Pd ${ }^{\mathrm{II}}$ catalyst; cf. Figure 8B).

\section{Catalytic mechanism: Overview of observations}

The data presented above provide key insights into the $\mathrm{DAF} / \mathrm{Pd}^{\mathrm{II}}(\mathrm{OAc})_{2}$-catalyzed acetoxylation of allylic $\mathrm{C}-\mathrm{H}$ bonds, including factors that affect the rate of the reaction and the identity of the catalyst resting state (Table 2). Briefly, the kinetic burst phase evident at the beginning of the reaction is characterized by a primary deuterium KIE (independent rate measurement) and a lack of rate-dependence on $p \mathrm{O}_{2}$, and the Pd catalyst evolves from a DAF-ligated $\mathrm{Pd}^{\mathrm{II}}$-acetate species into a DAF-bridged $\mathrm{Pd}^{\mathrm{I}}$ dimer. The ensuing post-burst 
phase lacks a primary KIE, exhibits a rate-dependence on $p \mathrm{O}_{2}$, and the Pd catalyst resting state evolves from the DAF-bridged $\mathrm{Pd}^{\mathrm{I}}$ dimer into $\pi$-allyl-Pd ${ }^{\mathrm{II}}$ species with bound and unbound DAF ligand.

\section{Analysis of the burst phase of the reaction}

The deuterium kinetic isotope effect observed during the burst supports allylic $\mathrm{C}-\mathrm{H}$ activation as the rate-limiting step during this phase. ${ }^{90,94,95}$ The resulting allyl-Pd ${ }^{\mathrm{II}}$ intermediate undergoes reductive elimination of cinnamyl acetate to afford a $\mathrm{Pd}^{0}$ species that reacts with a DAF/Pd ${ }^{\mathrm{II}}(\mathrm{OAc})_{2}$ species to afford the $\mathrm{Pd}^{\mathrm{I}}$ dimer 2 (Scheme 3; cf. Figure 14). The mechanistic details of reduction elimination and $\mathrm{Pd}^{\mathrm{II}} / \mathrm{Pd}^{0}$ comproportionation steps are not well understood and warrant attention in future studies, but formation of analogous dimeric $\mathrm{Pd}^{\mathrm{I}}$ species has been studied extensively in Pd-catalyzed cross-coupling reactions. ${ }^{52,96} \mathrm{Pd}^{\mathrm{I}}$ species have also been identified in oxidative carbonylation reactions, ${ }^{97-100}$ but the DAF-ligated dimer 2 represents the first example of a $\mathrm{Pd}^{\mathrm{I}}$ intermediate identified in ligandsupported Pd-catalyzed aerobic oxidation reactions. ${ }^{70} \mathrm{~A}$ second example was recently reported by Albéniz and Maseras, who detected a $\mathrm{Pd}^{\mathrm{I}}$ dimer in the aerobic oxidative homocoupling of alkynes with $\mathrm{Ph}_{3} \mathrm{P}$ as an ancillary ligand. ${ }^{101}$ The use of $\mathrm{Pd}^{\mathrm{I}}$ dimers as airstable catalyst precursors in many non-oxidative coupling reactions reactions ${ }^{52}$ raises prospects for similar opportunities in aerobic oxidation reactions.

\section{Analysis of the post-burst phase of the reaction}

The burst phase concludes as DAF-ligated $\mathrm{Pd}^{\mathrm{II}}$-acetate species are depleted and the $\mathrm{Pd}^{\mathrm{I}}$ dimer concentration reaches a maximum. The collection of kinetic and spectroscopic insights obtained from the reaction following the burst are incorporated into the overall catalytic mechanism proposed in Scheme 4. Previous studies have shown that the $\mathrm{Pd}^{\mathrm{I}}$ dimer can undergo oxidation to a DAF/Pd ${ }^{\mathrm{II}}$-acetate species in the presence of $\mathrm{O}_{2},{ }^{70,102}$ and the NMR data in Figure 10 show that allylbenzene promotes the conversion of $\mathrm{Pd}^{\mathrm{I}}$ dimer into a new $\mathrm{Pd}^{\mathrm{II}}$ form of the catalyst, identified as the allyl-PdII species $\mathbf{3}$ (cf. Figure 12), which serves as the catalyst resting state following the burst. This structure is consistent with the appearance of free DAF ligand under these conditions. The stoichiometric reactivity studies with 3, depicted in Figure 14, show that reductive elimination of cinnamyl acetate ${ }^{57}$ is promoted by DAF, $\mathrm{O}_{2}$, and $\mathrm{DAF} / \mathrm{Pd}(\mathrm{OAc})_{2}$; however, following the burst, excess DAF/ $\mathrm{Pd}(\mathrm{OAc})_{2}$ species are no longer available in the reaction mixture to promote reductive elimination. This difference between the burst and post-burst conditions rationalizes the change in catalyst speciation and turnover-limiting steps (cf. Table 2). These changes, in turn, account for the lack of a deuterium KIE for $\mathrm{C}-\mathrm{H}$ activation during the post-burst phase of the reaction and the similarity between the of post-burst turnover rate and the rate of the reaction when $\pi$-allyl-Pd ${ }^{\mathrm{II}}$ dimer $\mathbf{3}$ is used as the pre-catalyst (cf. Figure 13).

DAF plays an important role in supporting catalytic turnover under steady-state (post-burst) conditions by facilitating reductive elimination of cinnamyl acetate from the allyl-Pd ${ }^{\mathrm{II}}$ species. DAF coordination to the allyl-Pd ${ }^{\mathrm{II}} \operatorname{dimer} \mathbf{3}$ is proposed to generate the monomeric DAF-ligated allyl-PdII species 4 , which can undergo reversible formation of cinnamyl acetate (Figure 15). ${ }^{31,58}$ This reaction is driven by trapping of $\mathrm{Pd}^{0}(7)$ by $\mathrm{O}_{2}$, which is proposed to be the turnover limiting step during this phase of the reaction (Table 2). ${ }^{103,104}$ 
No build-up of $\mathrm{Pd}^{\mathrm{I}}$ dimer $\mathbf{2}$ is observed after the burst phase due to the low steady-state concentration of the $\mathrm{DAF} / \mathrm{Pd}^{\mathrm{II}}$-acetate species available to trap $\mathrm{Pd}^{0}$ species generated in the reductive elimination step. The reaction of $\mathrm{O}_{2}$ with the $\mathrm{Pd}^{0}$ species $\mathbf{7}$ is proposed to proceed in a manner similar to previously reported reactions between $\mathrm{O}_{2}$ and related well-defined nitrogen-chelated $\mathrm{Pd}^{0}$ model complexes. ${ }^{41,105-107}$

As noted in the Introduction, very few mechanistic studies of Pd-catalyzed allylic oxidation reactions have been reported. The two most thorough precedents were reported recently by the groups of Labinger/Bercaw ${ }^{10}$ and Fristrup, ${ }^{94}$ and focused on bipyrimidine (bpym)/ $\mathrm{Pd}^{\mathrm{II}}(\mathrm{OAc})_{2}$ and bis(sulfoxide)/ $\mathrm{Pd}^{\mathrm{II}}(\mathrm{OAc})_{2}$ catalyst systems, respectively. The turnoverlimiting step in the former reaction was identified as alkene binding to (bpym) $\mathrm{Pd}^{\mathrm{II}}(\mathrm{OAc})_{2}$, while the latter reaction was attributed to $\mathrm{C}-\mathrm{H}$ activation. The presence of a $\pi$-allyl-Pd ${ }^{\mathrm{II}}$ catalyst resting state and turnover-limiting reductive elimination are unprecedented, and these two observations likely reflect the use of $\mathrm{O}_{2}$, rather than benzoquinone, as the stoichiometric oxidant. Benzoquinone was used as the stoichiometric oxidant in both of the previously studied catalytic reactions, and it is known to promote reductive elimination from $\pi$-allyl-Pd ${ }^{\mathrm{II}}$ species. ${ }^{7,58,108,109}$ These considerations highlight opportunities for the development of improved catalyst systems and/or ligand designs that support more effective reductive elimination while also enabling efficient reaction of $\mathrm{Pd}^{0}$ with $\mathrm{O}_{2}$. Efforts toward this end have been initiated.

\section{Conclusion}

This study has implemented a number of different experimental approaches to gain insights into a Pd-catalyzed allylic oxidation reaction that is capable of using $\mathrm{O}_{2}$ as the stoichiometric oxidant due to the use of 4,5-diazafluoren-9-one (DAF) as an ancillary ligand. Operando XAS and NMR spectroscopic studies provide clear evidence for two kinetic phases, characterized by different catalyst resting states and turnover-limiting steps. The initial burst phase features the formation of an unusual DAF-bridged dimeric $\mathrm{Pd}^{\mathrm{I}}$ species, which then evolves into a $\pi$-allyl-Pd ${ }^{\mathrm{II}}$ catalyst resting state following the burst phase of the reaction. Allylic $\mathrm{C}-\mathrm{H}$ activation is the rate determining step during the burst phase, while catalyst reoxidation by $\mathrm{O}_{2}$ is turnover-limiting following the burst. The results described herein provide valuable new insights into this widely studied catalytic reaction, perhaps most importantly shedding light on the contribution of ancillary ligands to key steps in the catalytic mechanism. These insights provide a foundation for the exploration of new ancillary ligands and catalyst designs capable of efficient $\mathrm{Pd}$-catalyzed allylic $\mathrm{C}-\mathrm{H}$ oxidation.

\section{Supplementary Material}

Refer to Web version on PubMed Central for supplementary material.

\section{ACKNOWLEDGMENT}

We would like to thank Dr. Nicholas J. Beach, Mr. Steve Myers and Mr. Kendall Schneider for their assistance in designing and constructing the reactor used at Argonne. Drs. James R. Gallagher and James B. Gerken were instrumental in performing XAS experiments on the beamline. We are grateful to Dr. Kelsey Miles, Dr. Brian Dolinar and Dr. Ilia Guzei for assistance in performing XRD analysis. Drs. Jamie Y. C. Chen and Paul White for 
insightful discussions. This work was funded by the NSF (CHE-1665120), and builds upon initial work supported by the NIH (R01 GM67173). NMR instrumentation was supported by NSF CHE-1048642, NSF CHE-9709065, NIH S10 OD012245 and a generous gift from Paul J. and Margaret M. Bender. The WiHP-NMRR was supported by the Dow Chemical Company. Use of the Advanced Photon Source is supported by the U.S. Department of Energy, Office of Science, and Office of Basic Energy Sciences, under Contract DE-AC02-06CH11357. MRCAT operations are supported by the Department of Energy and the MRCAT member institutions. C. V. K. was supported in part by the National Science Foundation Graduate Research Fellowship Program under Grant No. DGE-1256259. Any opinions, findings, and conclusions or recommendations expressed in this material are those of the authors and do not necessarily reflect the views of the National Science Foundation. Support was also provided by the Graduate School and the Office of the Vice Chancellor for Research and Graduate Education at the University of Wisconsin-Madison with funding from the Wisconsin Alumni Research Foundation.

\section{References}

1. Smidt J; Hafner W; Jira R; Sedlmeier J; Sieber R; Ruttinger R; Kojer H Katalytische Umsetzungen von Olefinen an Platinmetall-Verbindungen. Angew. Chem 1959, 71, 176.

2. Vargaftik MN; Moiseev II; Syrkin Ya. K. Formation of Mixed Allyl Esters During Reaction of Higher Olefins with Palladium Chloride in Anhydrous Carboxylic Acid Solutions. Izv. Akad. Nauk SSSR 1962, 5, 930-931.

3. Anderson CB; Winstein S Synthesis of the Tricyclo[3.2.1.0 $\left.0^{3,6}\right]$ octane System. J. Org. Chem 1963, 28, 605-606.

4. For a recent review, see: Liron F; Oble J; Lorion MM; Poli G Direct Allylic Functionalization Through Pd-Catalyzed C-H Activation. Eur. J. Org. Chem 2014, 5863-5883.

5. McMurry JE; Kočovsky P A Method for the Palladium-Catalyzed Allylic Oxidation of Olefins. Tet. Lett 1984, 25, 4187-4190.

6. Åkermark B; Hansson S, Rein T; Vågberg J; Heumann A; Bäckvall J-E Palladium-Catalyzed Allylic Acetoxylation: an Exploratory Study of the Influence of Added Acids J. Org. Chem 1989, 369, 433-444.

7. Chen MS; White MC A Sulfoxide-Promoted, Catalytic Method for the Regioselective Synthesis of Allylic Acetates from Monosubstituted Olefins via C-H Oxidation. J. Am. Chem. Soc 2004, 126, 1346-1347. [PubMed: 14759185]

8. Chen MS; Prabagaran N; Labenz NA; White MC Serial Ligand Catalysis: A Highly Selective Allylic C-H Oxidation. J. Am. Chem. Soc 2005, 127, 6970-6971. [PubMed: 15884938]

9. Covell DJ; White MC A Chiral Lewis Acid Strategy for Enantioselective Allylic C-H Oxidation. Angew. Chem. Int. Ed 2008, 47, 6448-6451.

10. Lin B-L; Labinger JA; Bercaw JE Mechanistic Investigations of Bipyrimidinepromoted PalladiumCatalyzed Allylic Acetoxylation of Olefins. Can. J. Chem 2009, 87, 264-271.

11. Thiery E; Aouf C; Belloy J; Harakat D; Le Bras J; Muzart J Palladium-Catalyzed Allylic Acyloxylation of Terminal Alkenes in the Presence of a Base. J. Org. Chem 2009, 75, 1771-1774.

12. Kondo H; Yu F; Yamaguchi J; Liu G; Itami K Branch-Selective Allylic C-H Carboxylation of Terminal Alkenes by Pd/sox Catalyst. Org. Lett 2014, 16, 4212-4215. [PubMed: 25068764]

13. Malik HA; Taylor BLH; Kerrigan JR; Grob JE; Houk KN; Du Bois J; Hamann LG; Patterson AW Non-Directed Allylic C-H Acetoxylation in the Presence of Lewis Basic Heterocycles. Chem. Sci 2014, 5, 2352-2361. [PubMed: 25685311]

14. Heumann A; Reglier M; Waegell B Oxidation with Palladium Salts: Stereo- and Regiospecific Acetoxylation of 4-Vinylcyclohexene Derivatives. Angew. Chem. Int. Ed. Engl 1982, 21, 366-367.

15. Firdoussi LE; Baqqa A; Allaoud S; Allal BA; Karim A; Catanet Y; Mortreux A Selective Palladium-Catalysed Functionalization of Limonene: Synthetic and Mechanistic aspects. J. Mol. Catal. A: Chem 1998, 135, 11-22.

16. Jia C; Müller P; Mimoun H Palladium-Catalyzed Allylic Acetoxylation of Olefins Using Hydrogen Peroxide as Oxidant. J. Mol. Catal. A: Chem 1995, 101, 127-136.

17. Pilarski LT; Janson PG; Szabó KJ Palladium-Catalyzed Selective Acyloxylation Using Sodium Perborate as Oxidant. J. Org. Chem 2011, 76, 1503-1506. [PubMed: 21250717] 
18. Xing X; O’Connor NR; Stoltz BM Palladium(II)-Catalyzed Allylic C-H Oxidation of Hindered Substrates Featuring Tunable Selectivity Over Extent of Oxidation. Angew. Chem. Int. Ed 2015, 54, 11186-11190.

19. Litman ZC; Sharma A; Hartwig JF Oxidation of Hindered Allylic C-H Bonds with Applications to the Functionalization of Complex Molecules. ACS Catal. 2017, 7, 1998-2001. [PubMed: 29910970]

20. Pilarski LT; Selander N; Bose D; Szabó KJ Catalytic Allylic C-H Acetoxylation and Benzoyloxylation via Suggested ( $\eta 3$-Allyl)palladium(IV) Intermediates. Org. Lett 2009, 11, 55185521. [PubMed: 19899750]

21. Alam R; Pilarski LT; Pershagen E; Szabó KJ Stereoselective Intermolecular Allylic C-H Trifluoroacetoxylation of Functionalized Alkenes. J. Am. Chem. Soc 2012, 134, 8778-8781. [PubMed: 22587753]

22. Bäckvall JE; Hopkins RB; Grennberg H; Mader MM; Awasthi AK Multistep Electron Transfer in Palladium-Catalyzed Aerobic Oxidations via a Metal Macrocycle-Quinone System. J. Am. Chem. Soc 1990, 112, 5160-5166.

23. Hansson S; Heumann A; Rein T, Åkermark B Preparation of Allylic Acetates from Simple Alkenes by Palladium(I1)-Catalyzed Acetoxylation. J. Org. Chem. 1990, 55, 975-984.

24. Larsson EM; Akermark B A Catalytic System for Allylic Acetoxylation Consisting of Palladium(II) and Nitrate and Using Oxygen as Final Oxidant. Tet. Lett 1993, 34, 2523-2526.

25. Principato B; Maffei M; Siv C; Buono G; Peiffer B Palladium Catalysed Allylic Acetoxylation of Dialkyl Allyl Phosphonates. Tetrahdron, 1996, 52, 2087-2096.

26. Gusevskaya E; Gonsalves JA Palladium(II) Catalyzed Oxidation of Naturally Occurring Terpenes with Dioxygen. J. Mol. Catal. A: Chem 1997, 121, 131-137.

27. Henderson WH; Check CT; Proust N; Stambuli JP Allylic Oxidations of Terminal Olefins Using a Palladium Thioether Catalyst. Org. Lett 2010, 12, 824-827. [PubMed: 20099865]

28. Thiery E; Aouf C; Belloy J; Harakat D; Le Bras J; Muzart J Palladium-Catalyzed Allylic Acyloxylation of Terminal Alkenes in the Presence of a Base. J. Org. Chem 2010, 75, 1771-1774. [PubMed: 20141222]

29. For a review of oxidation cocatalyst systems employing redox mediators in reactions beyond Pdcatalyzed oxidations, see: Piera J; Bäckvall J Catalytic Oxidation of Organic Substrates by Molecular Oxygen and Hydrogen Peroxide by Multistep Electron Transfer-A Biomimetic Approach. Angew. Chem. Int. Ed 2008, 47, 3506-3523.

30. Mitsudome T; Umetani T; Nosaka N; Mori K; Mizugaki T; Ebitani K; Kaneda K Convenient and Efficient Pd-Catalyzed Regioselective Oxyfunctionalization of Terminal Olefins by Using Molecular Oxygen as Sole Reoxidant. Angew. Chem. Int. Ed 2006, 45, 481-485.

31. Campbell AN; White PB; Guzei IA; Stahl SS Allylic C-H Acetoxylation with a 4,5Diazafluorenone-Ligated Palladium Catalyst: A Ligand-Based Strategy To Achieve Aerobic Catalytic Turnover. J. Am. Chem. Soc 2010, 132, 15116-15119. [PubMed: 20929224]

32. Fraunhoffer KJ; Prabagaran N; Sirois LE; White MC Macrolactonization via Hydrocarbon Oxidation. J. Am. Chem. Soc 2006, 128, 9032-9033. [PubMed: 16834366]

33. Stang EM; White MC Total Synthesis and Study of 6-Deoxyerythronolide B by Late-Stage C-H Oxidation. Nat. Chem 2009, 1, 547-551. [PubMed: 21378935]

34. Vermeulen NA; Delcamp JH; White MC Synthesis of Complex Allylic Esters via C-H Oxidation vs C-C Bond Formation. J. Am. Chem. Soc 2010, 132, 11323-11328. [PubMed: 20662536]

35. Trost BM; Thaisrivongs DA; Donckele EJ Palladium-Catalyzed Enantioselective Allylic Alkylations through C-H Activation. Angew. Chem. Int. Ed 2013, 52, 1523-1526.

36. Wang P-S; Liu P; Zhai Y-J; Lin H-C; Han Z-Y; Gong L-Z Asymmetric Allylic C-H Oxidation for the Synthesis of Chromans. J. Am. Chem. Soc 2015, 137, 12732-12735. [PubMed: 26400002]

37. Amman SE; Liu W; White MC Enantioselective Allylic C-H Oxidation of Terminal Olefins to Isochromans by Palladium(II)/Chiral Sulfoxide Catalysis. Angew. Chem. Int. Ed 2016, 55, 95719575.

38. Gormisky PE; White MC Synthetic Versatility in C-H Oxidations: A Rapid Approach to Differentiated Diols and Pyrans from Simple Olefins. J. Am. Chem. Soc 2011, 133, 12584-12589. [PubMed: 21744821] 
39. For discussion of ligand effects on Pd-catalyzed aerobic oxidation reactions, see the following and refs. 40 and 41: Stahl SS Palladium Oxidase Catalysis: Selective Oxidation of Organic Chemicals by Direct Dioxygen-Coupled Turnover. Angew. Chem. Int. Ed 2004, 43, 3400-3420.

40. Gligorich KM; Sigman MS Recent Advancements and Challenges of Palladium ${ }^{\mathrm{II}}$-Catalyzed Oxidation Reactions with Molecular Oxygen as the Sole Oxidant. Chem. Commun 2009, 38543867.

41. Wang D; Weinstein AB; White PB; Stahl SS Ligand-Promoted Palladium-Catalyzed Aerobic Oxidation Reactions. Chem. Rev 2018, 118, 2636-2679. [PubMed: 28975795]

42. Amatore C; Jutand A Mechanistic and Kinetic Studies of Palladium Catalytic Systems. J. Organomet. Chem 1999, 576, 254-278.

43. Metal-Catalyzed Cross-Coupling Reactions. de Meijere A; Diederich F, Eds.; Wiley-VCH, Weinheim, 2004, and references therein.

44. Blackmond DG Reaction Progress Kinetic Analysis: A Powerful Methodology for Mechanistic Studies of Complex Catalytic Reactions. Angew. Chem. Int. Ed 2005, 44, 4302-4320.

45. Hartwig JF Carbon-heteroatom Bond Formation Catalyzed by Organometallic Complexes. Nature 2008, 455, 314-322. [PubMed: 18800130]

46. Rosner T; LeBars J; Pfaltz A; Blackmond DG Kinetic Studies of Heck Coupling Reactions Using Palladacycle Catalysts: Experimental and Kinetic Modeling of the Role of Dimer Species. J. Am. Chem. Soc 2001, 123, 1848-1855. [PubMed: 11456804]

47. Alvaro E; Hartwig JF Resting State and Elementary Steps of the Coupling of Aryl Halides with Thiols Catalyzed by Alkylbisphosphine Complexes of Palladium. J. Am. Chem. Soc 2009, 131, 22, 7858-7868. [PubMed: 19453106]

48. Seechurn CCCJ; Sperger T; Scrase TG; Schoenebeck F; Colacot TJ Understanding the Unusual Reduction Mechanism of Pd(II) to Pd(I): Uncovering Hidden Species and Implications in Catalytic Cross-Coupling Reactions. J. Am. Chem. Soc, 2017, 139, 5194-5200. [PubMed: 28300400]

49. Surry DS; Buchwald SL Biaryl Phosphane Ligands in Palladium-Catalyzed Amination. Angew. Chem. Int. Ed 2008, 47, 6338-6361.

50. Fortman GC; Nolan SP N-Heterocyclic Carbene (NHC) Ligands and Palladium in Homogeneous Cross-Coupling Catalysis: A Perfect Union. Chem. Soc. Rev 2011, 40, 5151-5169. [PubMed: 21731956]

51. Valente C; Pompeo M; Sayah M; Organ MG Carbon-Heteroatom Coupling Using Pd-PEPPSI Complexes. Org. Process Res. Dev 2014, 18, 180-190.

52. Hazari N; Hruszkewycz DP Dinuclear Pd ${ }^{\mathrm{I}}$ Complexes with Bridging Allyl and Related Ligands. Chem. Soc. Rev 2016, 45, 2871-2899. [PubMed: 27051890]

53. Gildner PG; Colacot TJ Reactions of the 21st Century: Two Decades of Innovative Catalyst Design for Palladium-Catalyzed Cross-Couplings. Organometallics 2015, 34, 5497-5508.

54. Littke AF; Fu GC Palladium-Catalyzed Coupling Reactions of Aryl Chlorides. Angew. Chem. Int. Ed 2002, 41, 4176-4211.

55. White PB; Jaworski JN; Fry CG; Dolinar BS; Guzei IA; Stahl SS Structurally Diverse Diazafluorene-Ligated Palladium(II) Complexes and Their Implications for Aerobic Oxidation Reactions. J. Am. Chem. Soc 2016, 138, 4869-4880. [PubMed: 26967703]

56. For a review of the rich DAF coordination chemistry with various transition metals, see: Annibale VT; Song D Coordination Chemistry and Applications of Versatile 4,5-Diazafluorene Derivatives. Dalton Trans. 2016, 45, 32-49. [PubMed: 26621438]

57. For simplicity, the term "reductive elimination" is applied to the step generating allyl acetate from the allyl-PdII intermediate. Although the mechanism of this reaction could proceed via innersphere or outer-sphere attack of an acetate on the allyl ligand, both pathways result in the "reduction" of PdII to Pd0 and the "elimination" of allyl acetate as the product. For context, similar usage of the term "reductive elimination" is applied to the formation of C-X bonds from d6 octahedral metal complexes, even when the $\mathrm{C}-\mathrm{X}$ bond is formed via outer-sphere attack of the nucleophile. See, for example: Williams BS; Goldberg KI Studies of Reductive Elimination Reactions To Form Carbon-Oxygen Bonds from Pt(IV) Complexes. J. Am. Chem. Soc 2001, 123, 2576-2587. [PubMed: 11456927] 
58. Diao T; Stahl SS O2-Promoted Allylic Acetoxylation of Alkenes: Assessment of "Push" versus "Pull" Mechanisms and Comparison Between O2 and Benzoquinone. Polyhedron 2014, 84, 96102. [PubMed: 25435646]

59. The beneficial effect of DAF has been demonstrated in a number of Pd-catalyzed oxidation reactions beyond allylic oxidation. See references 60-69.

60. White PB; Jaworski JN; Geyunjian HZ; Stahl SS Diazafluorenone-Promoted Oxidation Catalysis: Insights into the Role of Bidentate Ligands in Pd-Catalyzed Aerobic Aza-Wacker Reactions. ACS Catal. 2016, 6, 3340-3348. [PubMed: 27175308]

61. Campbell AN; Meyer EB; Stahl SS Regiocontrolled Aerobic Oxidative Coupling of Indoles and Benzene using Pd Catalysts with 4,5-Diazafluorene Ligands. Chem. Commun 2011, 47, 1025710259.

62. Xia B; Gong TJ; Liu Z-J; Liu J-H; Luo D-F; Xu J; Liu L Synthesis of Dibenzofurans via Palladium-Catalyzed Phenol-Directed C-H Activation/C-O Cyclization. J. Am. Chem. Soc 2011, 133, 9250-9253. [PubMed: 21609019]

63. Piotrowicz M; Zakrzewski J Aerobic Dehydrogenative Heck Reaction of Ferrocene with a Pd(OAc)2/4,5-Diazafluoren-9-one Catalyst. Organometallics 2013, 32, 5709-5712.

64. Piotrowicz M; Zakrewski Métivier, R.; Brosseau A; Makal A; Woźniak K Aerobic Palladium(II)Catalyzed Dehydrogenative Heck Reaction in the Synthesis of Pyrenyl Fluorophores. A Photophysical Study of $\beta$-Pyrenyl Acrylates in Solution and in the Solid State. J. Org. Chem 2015, 80, 2573-2581. [PubMed: 25642784]

65. Vasseur A; Laugel C; Harakat D; Muzart J; Le Bras J Ligand-Promoted Reactivity of Alkenes in Dehydrogenative Heck Reactions of Furans and Thiophenes. Eur. J. Org. Chem 2015, 5, 944-948.

66. Kim HT; Ha H; Kang G; Kim OS; Ryu H; Biswas AK; Lim SM; Baik M-H; Joo JM Ligandcontrolled Regiodivergent C-H Alkenylation of Pyrazoles and its Application to the Synthesis of Indazoles. Angew. Chem. Int. Ed 2017, 56, 16262-16266.

67. Gao WM; He ZQ; Qian Y; Zhao J; Huang Y General Palladium-Catalyzed Aerobic Dehydrogenation to Generate Double Bonds. Chem. Sci 2012, 3, 883-886.

68. Diao T; Wadzinski TJ; Stahl SS Direct Aerobic a,b-Dehydrogenation of Aldehydes and Ketones with a Pd(TFA)2/4,5-Diazafluorenone Catalyst. Chem. Sci 2012, 3, 887-891. [PubMed: 22690316]

69. Buter J; Moezelaar R; Minnaard AJ Enantioselective Palladium Catalyzed Conjugate Additions of Ortho-Substituted Arylboronic Acids to $\beta, \beta$-Disubstituted Cyclic Enones: Total Synthesis of Herbertenediol, Enokipodin A and Enokipodin B. Org. Biomol. Chem 2014, 12, 5883-5890. [PubMed: 24984187]

70. Jaworski JN; McCann SD; Guzei IA; Stahl SS Detection of Palladium(I) in Aerobic Oxidation Catalysis. Angew. Chem. Int. Ed 2017, 56, 3605-3610.

71. High yields of product formation ( $>40 \%$ yield) could not be obtained at $60{ }^{\circ} \mathrm{C}$, the previously reported optimized reaction temperature, but were possible at $80^{\circ} \mathrm{C}$. Therefore, kinetic investigations were generally performed at $80^{\circ} \mathrm{C}$.

72. Nelson RC; Miller JT An Introduction to X-ray Absorption Spectroscopy and its in situ Application to Organometallic Compounds and Homogeneous Catalysts. Catal. Sci. Tech 2012, 2, 461-470.

73. Sherborne GJ; Nguyen BN Recent XAS studies into Homogeneous Metal Catalyst in Fine Chemical and Pharmaceutical Syntheses. Chem. Cent. J 2015, 9, 37. [PubMed: 26140050]

74. For other representative applications of XAS to the analysis of molecular Pd complexes and Pdcatalyzed reactions, see the following and refs. 75-79: Evans J; O'Neill L; Kambhampati VL; Rayner G; Turin S; Genge A; Dent AJ; Neisius T Structural Characterisation of Solution Species Implicated in the Palladium-Catalysed Heck Reaction by Pd K-edge X-ray Absorption Spectroscopy: Palladium Acetate as a Catalyst Precursor. Dalton Trans. 2002, 2207-2212.

75. Tromp M; Sietsma JRA; van Bokhoven JA; van Strijdonck GPF; van Haaren RJ; van der Eerden AMJ; van Leeuwen PWNM; Koningsberger DC Deactivation Processes of Homogeneous Pd Catalysts using in situ Time Resolved Spectroscopic Techniques. Chem. Commun 2003, 128-129. 
76. Fiddy SG; Evans J; Newton MA; Neisius T; Tooze RP; Oldman R Extended X-ray Absorption Fine Structure (EXAFS) Characterisation of Dilute Palladium Homogeneous Catalysts. Chem. Commun 2003, 2682-2683.

77. Tromp M; van Bokhoven JA; van Strijdonck GPF; van Leeuwen PWNM; Koningsberger DC; Ramaker DE Probing the Molecular Orbitals and Charge Redistribution in Organometallic (PP)Pd(XX) Complexes. A Pd K-Edge XANES Study. J. Am. Chem. Soc 2005, 127, 777-789. [PubMed: 15643904]

78. Fiddy SG; Evans J; Neisius T; Newton MA; Tsoureas N; Tulloch AAD; Danopoulos AA Comparative Experimental and EXAFS Studies in the Mizoroki-Heck Reaction with HeteroatomFunctionalised N-Heterocyclic Carbene Palladium Catalysts. Chem. Eur. J 2007, 13, 3652-3659. [PubMed: 17304612]

79. MacMillan SN; Lancaster KM X-ray Spectroscopic Interrogation of Transition-Metal-Mediated Homogeneous Catalysis: Primer and Case Studies. ACS Catal. 2017, 7, 1776-1791.

80. Tereniak SJ; Stahl SS Mechanistic Basis for Efficient, Site-Selective, Aerobic Catalytic Turnover in Pd-Catalyzed C-H Imidoylation of Heterocycle- Containing Molecules. J. Am. Chem. Soc 2017, 139, 14533-14541. [PubMed: 28942639]

81. Reaction conditions for the operando XANES study: $[\mathrm{Pd}(\mathrm{OAc}) 2]=[\mathrm{DAF}]=13.5 \mathrm{mM},[\mathrm{NaOAc}]=$ $54 \mathrm{mM}$, [allylbenzene] $=0.27 \mathrm{M}$, total reaction mixture was $3 \mathrm{~mL}$ in $3: 1$ dioxane/AcOH. The reaction was run at $80{ }^{\circ} \mathrm{C}$ with a stir rate of $700 \mathrm{rpm}$. $\mathrm{O} 2$ was provided via a balloon using a custom PEEK cell (details in Supporting Information). Spectra were acquired from the region of $24.1 \mathrm{keV}$ to $25.1 \mathrm{keV}$ with a frequency of approximately $0.4 \mathrm{eV}$.

82. Previous high-pressure NMR experiments in the Stahl group have been performed using JYoung tubes and condensing known amount of $\mathrm{O} 2$ with liquid nitrogen. See refs. 83-84 for pertinent examples. However, a safer and easier method was realized using components available from Wilmad-Labglass. These experiments are only adequate for studying the beginning phase of the reaction as there is not a mechanism for mixing the reaction solution and replenishing consumed $\mathrm{O} 2$ using static tubes. Deconvoluting mass-transport phenomena from chemical reaction kinetics can become challenging at extended time points. See supporting information for additional details.

83. Steinhoff BA; Guzei IA; Stahl SS Mechanistic Characterization of Aerobic Alcohol Oxidation Catalyzed by $\mathrm{Pd}(\mathrm{OAc}) 2 /$ Pyridine Including Identification of the Catalyst Resting State and the Origin of Nonlinear [Catalyst] Dependence. J. Am. Chem. Soc 2004, 126, 11268-11278. [PubMed: 15355108]

84. Ye X; Liu G; Popp BV; Stahl SS Mechanistic Studies of Wacker-Type Intramolecular Aerobic Oxidative Amination of Alkenes Catalyzed by Pd(OAc)2/Pyridine. J. Org. Chem 2011, 76, 10311044. [PubMed: 21250706]

85. Beach NJ; Knapp SMM; Landis CR A Reactor for High-Throughput High-Pressure Nuclear Magnetic Resonance Spectroscopy. Rev. Sci. Instrum 2015, 86, 104101. [PubMed: 26520969]

86. Chotchatchawankul S, Mechanistic Studies of Rh(diphosphine)-Catalyzed Methanol Reductive Carbonylation, Dissertation, University of Wisconsin - Madison. Madison, WI, 2015.

87. Brezny AC; Landis CR Unexpected CO Dependencies, Catalyst Speciation, and Single Turnover Hydrogenolysis Studies of Hydroformylation via High Pressure NMR Spectroscopy. J. Am. Chem. Soc 2017, 139, 2778-2785. [PubMed: 28125782]

88. A gas mixture of $9 \% \mathrm{O} 2$ in $\mathrm{N} 2$ was used to mitigate flammability concerns, and a sapphire NMR tube allowed for the use of high gas pressures. For discussion of $\mathrm{O} 2$ flammability limits, see: Osterberg PM; Niemeier JK; Welch CJ; Hawkins JM; Martinelli JR; Johnson TE; Root T W; Stahl, S. S. Experimental Limiting Oxygen Concentrations for Nine Organic Solvents at Temperatures and Pressures Relevant to Aerobic Oxidations in the Pharmaceutical Industry. Org. Process Res. Dev 2015, 19, 1537-1543. [PubMed: 26622165]

89. Knapp SMM; Shaner SE; Kim D; Shopov DY; Tendler JA; Pudalov DM; Chianese AR Mechanistic Studies of Alkene Isomerization Catalyzed by CCC-Pincer Complexes of Iridium. Organometallics 2014, 33, 473-484.

90. Yin G; Wu Y; Liu G Scope and Mechanism of Allylic C-H Amination of Terminal Alkenes by the Palladium/PhI(OPiv)2 Catalyst System: Insights into the Effect of Naphthoquinone. J. Am. Chem. Soc 2010, 132, 11978-11987. [PubMed: 20690676] 
91. Powell J; Robinson SD; Shaw BL Intermediates in the Conversion of $\pi$-into $\sigma$-Allylic Palladium(II) Complexes. Chem. Commun. (London) 1965, 0, 78-79.

92. Powell J; Shaw BL Transition Metal-Carbon Bonds. Part X. Reactions between Allylic Palladium Halides and Tertiary Phosphines, Triphenylarsine, Triphenylstibine, or Carbon Monoxide. J. Chem. Soc. A 1967, 0, 1839-1851.

93. Jalón FA; Manzano BR; Otero A; Rodríguez-Pérez MC Synthesis and Fluxional Behaviour of Allylpalladium Complexes with Poly(pyrazol-1-yl)methane Ligands. J. Organomet. Chem 1995, 494, 179-185.

94. Engelin C; Jensen T; Rodriguez-Rodriguez S; Fristrup P Mechanistic Investigation of PalladiumCatalyzed Allylic C-H Activation. ACS Catal. 2013, 3, 294-302.

95. Gómez-Gallego M; Sierra MA Kinetic Isotope Effects in the Study of Organometallic Reaction Mechanisms. Chem. Rev 2011, 111, 4857-4963. [PubMed: 21545118]

96. Bonney KJ; Schoenebeck F Experiment and Computation: a Combined Approach to Study the Reactivity of Palladium Complexes in Oxidation States 0 to IV. Chem. Soc. Rev 2014, 43, 66096638. [PubMed: 24759955]

97. Xu Q; Souma Y; Umezawa J; Tanaka M; Nakatani H Palladium(I) Carbonyl Cation-Catalyzed Carbonylation of Olefins and Alcohols in Concentrated Sulfuric Acid. J. Org. Chem 1999, 64, 6306-6311.

98. Temkin ON; Bruk LG Palladium(II, I, 0) Complexes in Catalytic Reactions of Oxidative Carbonylation. Kinet. Catal 2003, 44, 601-617.

99. Stromnova TA Palladium(+1) Carbonyl Clusters in the Catalytic Oxidation of Unsaturated Compounds. Platinum Met. Rev 2003, 47, 20-27.

100. Ragaini F; Larici H; Rimoldi M; Caselli A; Ferretti F; Maachi P; Casati N Mapping Palladium Reduction by Carbon Monoxide in a Catalytically Relevant System. A Novel Palladium(I) Dimer. Organometallics 2011, 30, 2385-2393.

101. Toledo A; Funes-Ardoiz I; Maseras F; Albéniz AC Palladium-Catalyzed Aerobic Homocoupling of Alkynes: Full Mechanistic Characterization of a More Complex Oxidase-Type Behavior. ACS Catal. 2018, 8, 7495-7506.

102. For an example of direct reactivity between $\mathrm{O} 2$ and a PdI dimer, see: Huacuja R; Graham DJ; Fafard CM; Chen C-H; Foxman BM; Herbert DE; Alliger G; Thomas CM; Ozerov OV Reactivity of a Pd(I)-Pd(I) Dimer with O2: Mohohapto Pd Superoxide and Dipalladium Peroxide in Equilibrium. J. Am. Chem. Soc 2011, 13, 3820-3823.

103. Pd-catalyzed aerobic oxidation reactions rarely exhibit a kinetic dependence on $\mathrm{pO} 2$ and precedents typically arise from mass-transport limitations. In the present reaction, mass transport limitations may be ruled out on the basis of the increase in rate with higher [catalyst] and [allylbenzene]. If the $\mathrm{O} 2$ dependence reflected mass-transport limitations, the reaction rate should reach a plateau with a sharp break at higher [catalyst] and [allylbenzene], reflecting the $\mathrm{O} 2$ mass transport rate (cf. data for the oxidative amidation reaction in ref. 70). For another example of a Pd-catalyzed aerobic oxidation reaction that exhibits a positive order in pO2, see ref. 101.

104. Steinhoff BA; Stahl SS Mechanism of Pd(OAc)2/DMSO-Catalyzed Aerobic Alcohol Oxidation: Mass-Transfer-Limitation Effects and Catalyst Decomposition Pathways. J. Am. Chem. Soc 2006, 128, 4348-4355. [PubMed: 16569011]

105. Stahl SS; Thorman JL; Nelson RC; Kozee MA Oxygenation of Nitrogen-Coordinated Palladium(0): Synthetic, Structural, and Mechanistic Studies and Implications for Aerobic Oxidation Catalysis. J. Am. Chem. Soc 2001, 123, 7188-7189. [PubMed: 11459511]

106. Popp BV; Stahl SS “Oxidatively Induced” Reductive Elimination of Dioxygen from an $\eta 2-$ Peroxopalladium(II) Complex Promoted by Electron-Deficient Alkenes. J. Am. Chem. Soc 2006, 128, 2804-2805. [PubMed: 16506751]

107. Popp BV; Morales CM; Landis CR; Stahl SS Electronic Structural Comparison of the Reactions of Dioxygen and Alkenes with Nitrogen-Chelated Palladium(0). Inorg. Chem 2010, 49, 82008207. [PubMed: 20604535]

108. Bäckvall J-E; Gogoll A Evidence for ( $\pi$-allyl)Palladium(II)(quinone) Complexes in the Palladium-Catalyzed 1,4-Diacetoxylation of Conjugated Dienes. Tetrahedron Lett. 1988, 29 , 2243-2246. 
109. Grennber H; Gogoll A; Bäckvall J-E Use of Sulfoxides as Cocatalysts in the Palladium-QuinoneCatalyzed 1,4-Diacetoxylation of 1,3-Dienes. An Example of Ligand-Accelerated Catalysis. J. Org. Chem 1991, 56, 5808-5811. 

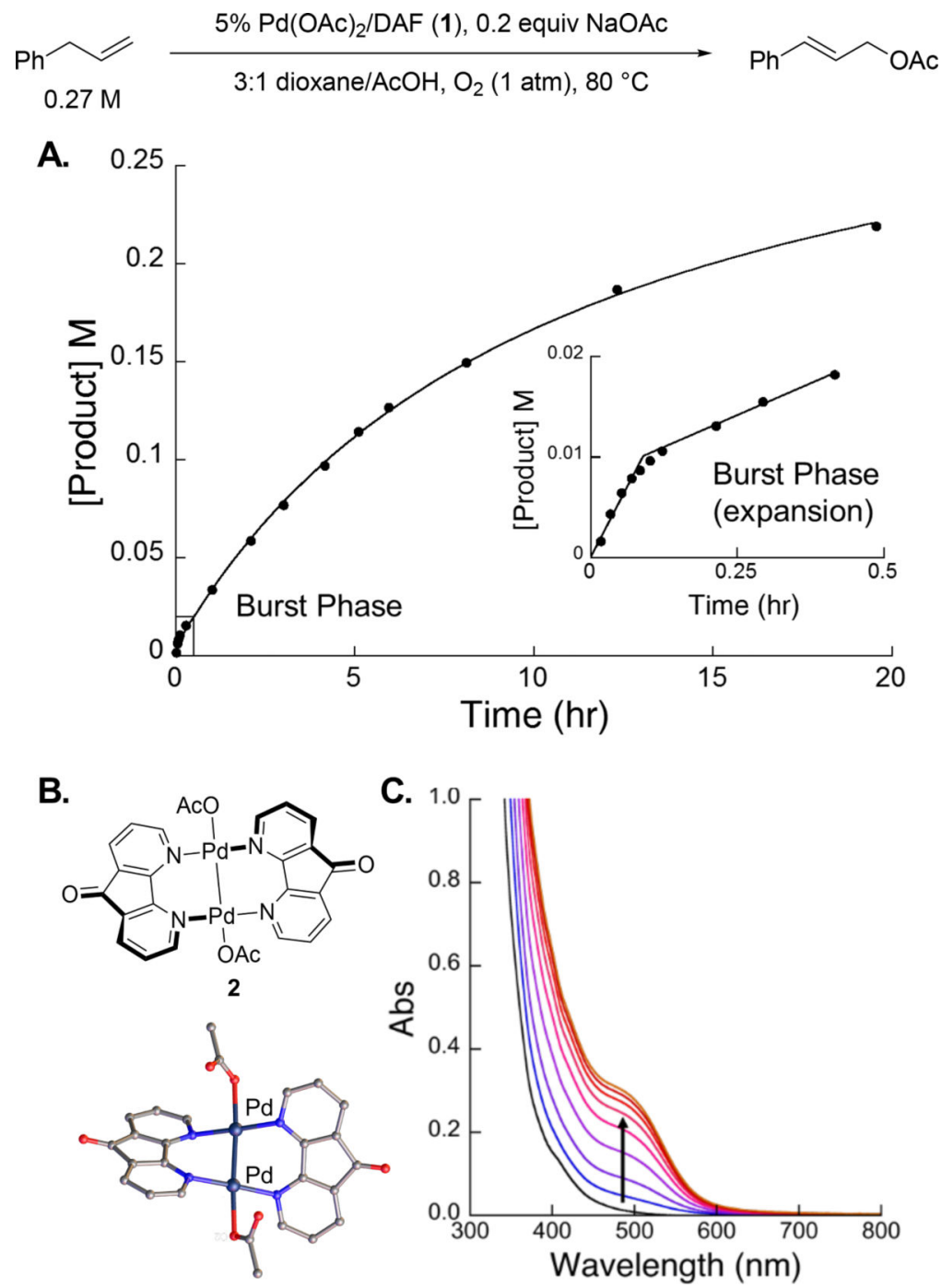

Figure 1.

Previous observations from allylic acetoxylation of allylbenzene catalyzed by DAF/ $\mathrm{Pd}(\mathrm{OAc})_{2}$. (A) Time course of the acetoxylation reaction at $80{ }^{\circ} \mathrm{C}$. (B) Drawing and X-ray crystal structure of the $\mathrm{Pd}^{\mathrm{I}}$ dimer, $\left[\mathrm{Pd}^{\mathrm{I}}(\mathrm{DAF})(\mathrm{OAc})\right]_{2}$ 2. (C) UV-vis absorption spectra obtained during the burst phase of the catalytic reaction. Figures adapted with permission from ref. 70. Copyright 2017 John Wiley \& Sons, Inc. 
A.

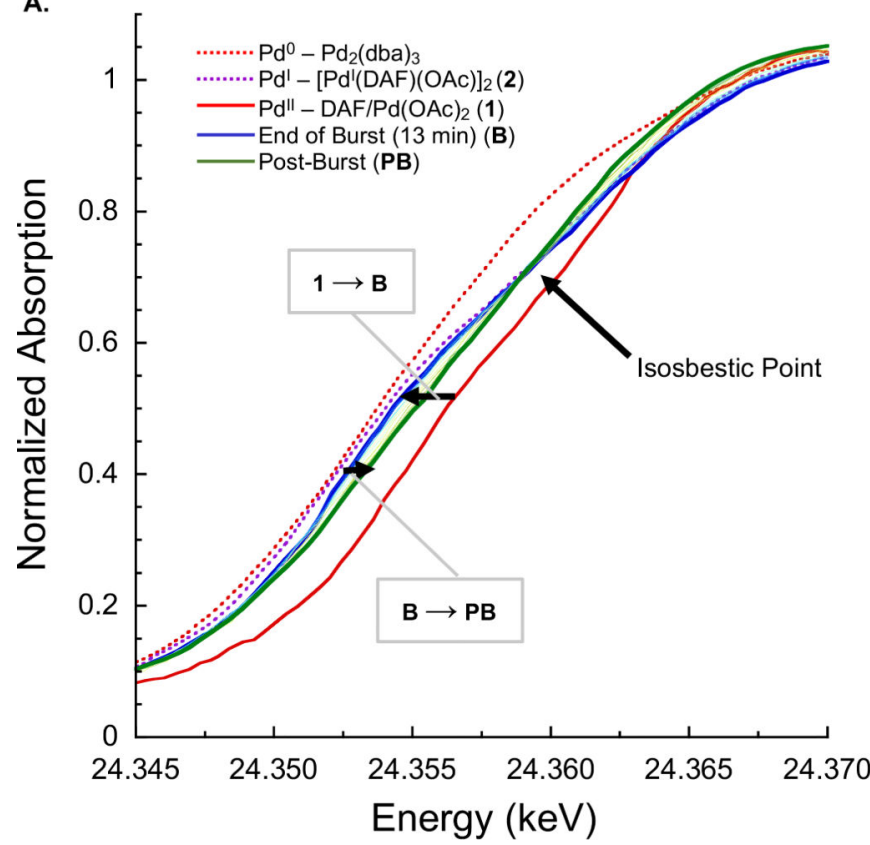

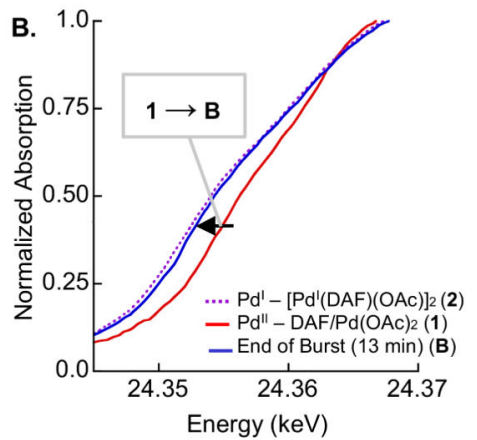

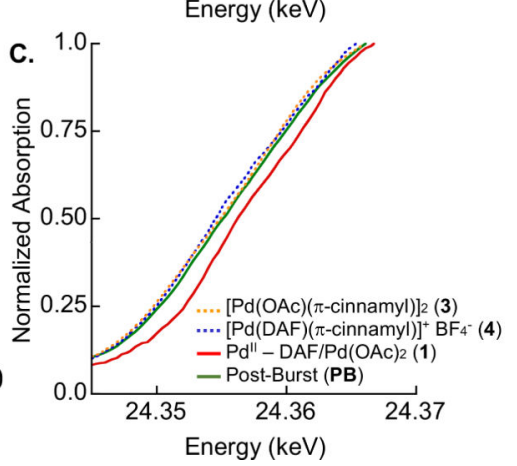

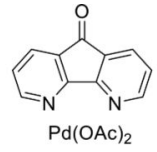

1<smiles>CC(=O)ON1C=CC=CC1</smiles><smiles>C1CCC(PNC2CCCC2)CC1</smiles>

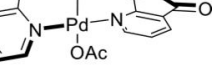
$[\underbrace{2}_{\mathrm{Ph}}]_{2}^{2}$ 3

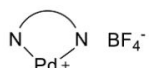
$\stackrel{P h}{P}$ $\mathrm{N} \sim \mathrm{N}=\mathrm{DAF}$ 4

Figure 2.

XAS K-edge analysis of Pd reference compounds and the catalyst during the allylic oxidation reaction (note: "B" refers to the "burst" phase and "PB" refers to the "post-burst" phase of the reaction). (A) Operando Pd K-edge time course overlay from 13-110 minutes with overlaid references for comparison. (B) Operando Pd K-edge time course overlay of 0 and 13 minutes with comparison of $\left[\mathrm{Pd}^{\mathrm{I}}(\mathrm{DAF})(\mathrm{OAc})\right]_{2}$ (2) reference. (C) Comparison of the post-burst with neutral $\pi$-allyl $\mathrm{Pd}^{\mathrm{II}}$ acetate dimer, $\left[\mathrm{Pd}^{\mathrm{II}}(\pi \text {-cinnamyl })(\mathrm{OAc})\right]_{2}(\mathbf{3})$ and cationic $\pi$-allyl $\mathrm{Pd}^{\mathrm{II}}$ monomer, $\left[\mathrm{Pd}^{\mathrm{II}}(\mathrm{DAF})(\pi\right.$-cinnamyl) $] \mathrm{BF}_{4}(\mathbf{4})$. The catalytic reaction was carried out on a $3 \mathrm{~mL}$ scale in 3:1 dioxane: $\mathrm{AcOH}$ where [allylbenzene] $=0.27 \mathrm{M}$, [NaOAc] $=0.54$ $\mathrm{mM}$, and $\left[\mathrm{DAF} / \mathrm{Pd}(\mathrm{OAc})_{2}\right]=13.5 \mathrm{mM}$ in a PEEK cell with an $\mathrm{O}_{2}$ balloon. 

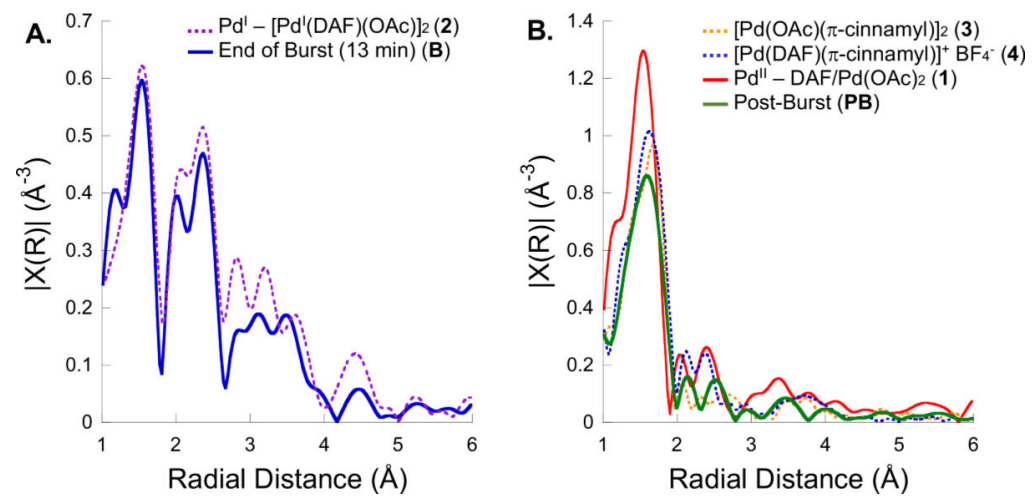

Figure 3.

Operando EXAFS $\mathrm{k}^{2}$-weighted four transforms at $t=13 \mathrm{~min}$ and post-burst turnover. (A) Comparison of the EXAFS at $t=13 \mathrm{~min}$ and $\mathrm{Pd} \mathrm{I}$ dimer $[\mathrm{Pd} \mathrm{I}(\mathrm{DAF})(\mathrm{OAc})]_{2}(2)$ reference. (B) Comparison of the EXAFS from the post-burst period of the catalytic reaction with DAF/ $\mathrm{Pd}(\mathrm{OAc})_{2}(\mathbf{1})$ and the $\pi$-allyl-Pd ${ }^{\mathrm{II}}$ reference compounds $(\mathbf{3})$ and (4). The catalytic reaction was carried out on a $3 \mathrm{~mL}$ scale in 3:1 dioxane: $\mathrm{AcOH}$ where [allylbenzene] $=0.27 \mathrm{M}$, $[\mathrm{NaOAc}]=0.54 \mathrm{mM}$, and $\left[\mathrm{DAF} / \mathrm{Pd}(\mathrm{OAc})_{2}\right]=13.5 \mathrm{mM}$ in a PEEK cell with an $\mathrm{O}_{2}$ balloon. 

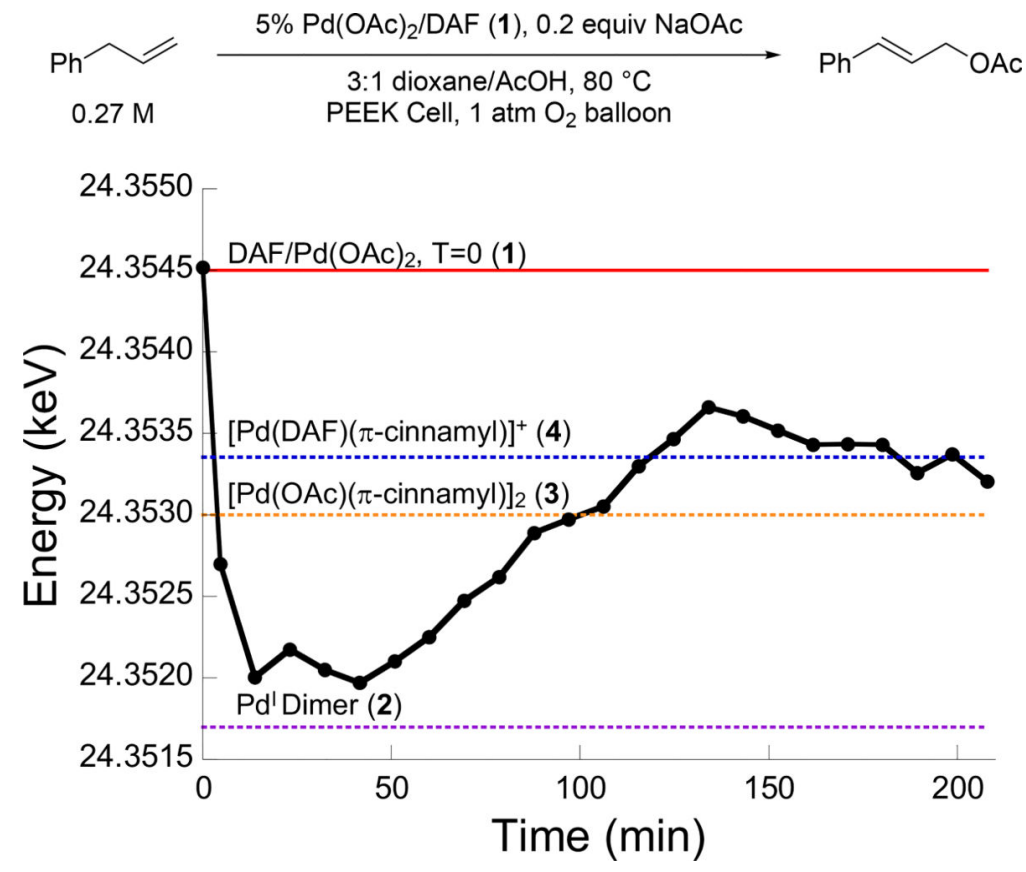

Figure 4.

Time course plot of the XANES edge energy of the Pd catalyst during the catalytic allylic acetoxylation reaction, relative to the edge energies corresponding to well-defined $\mathrm{Pd}$ reference compounds. 

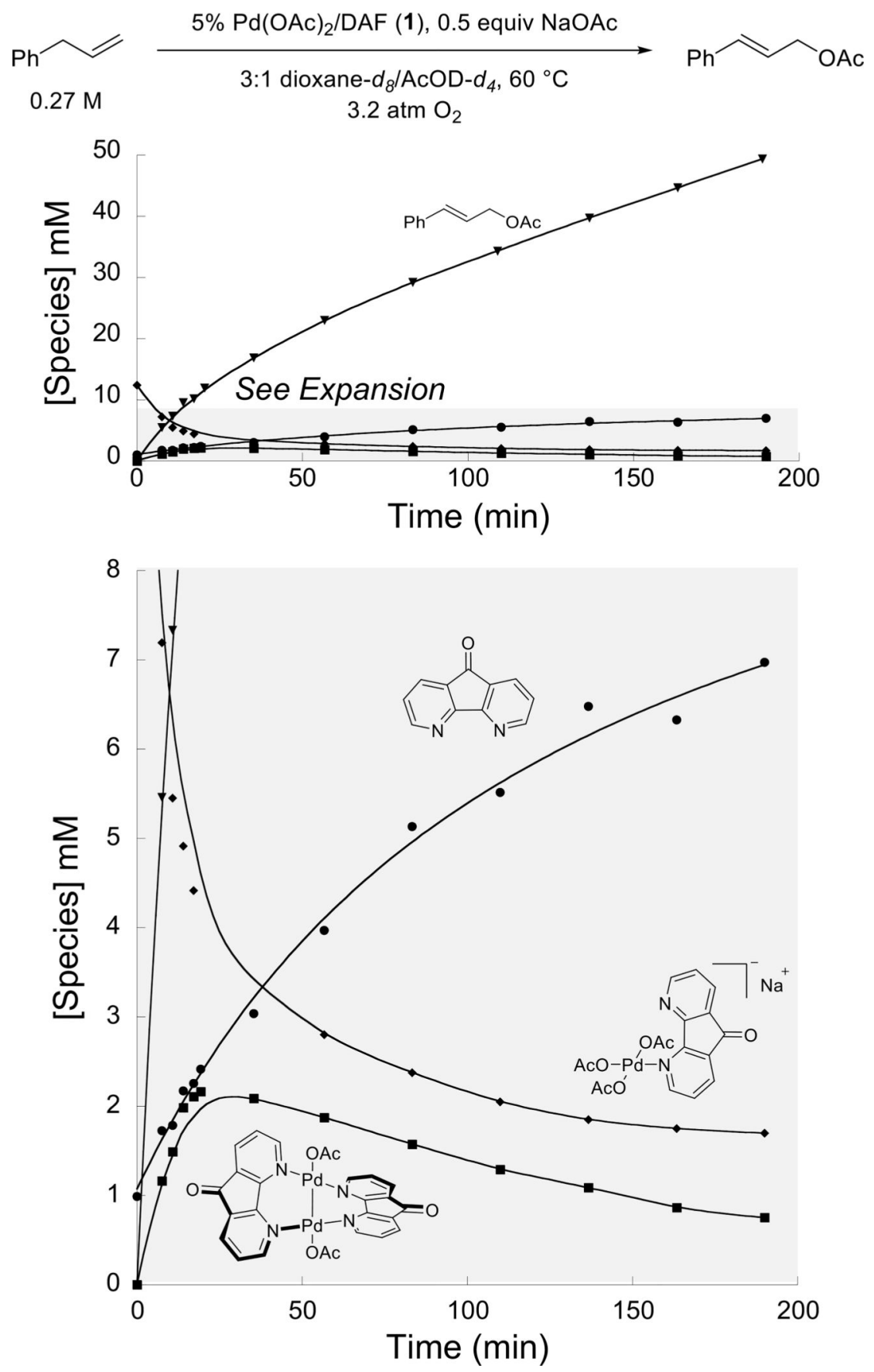

Figure 5.

Initial investigations into the resting state of the catalyst as followed by an NMR time course of product formation and DAF speciation with 3.2 atm static $\mathrm{O}_{2}$ at $60{ }^{\circ} \mathrm{C}$ and expansion of DAF speciation in the NMR time course. Lines reflect smooth fits to the data to guide the eye. 

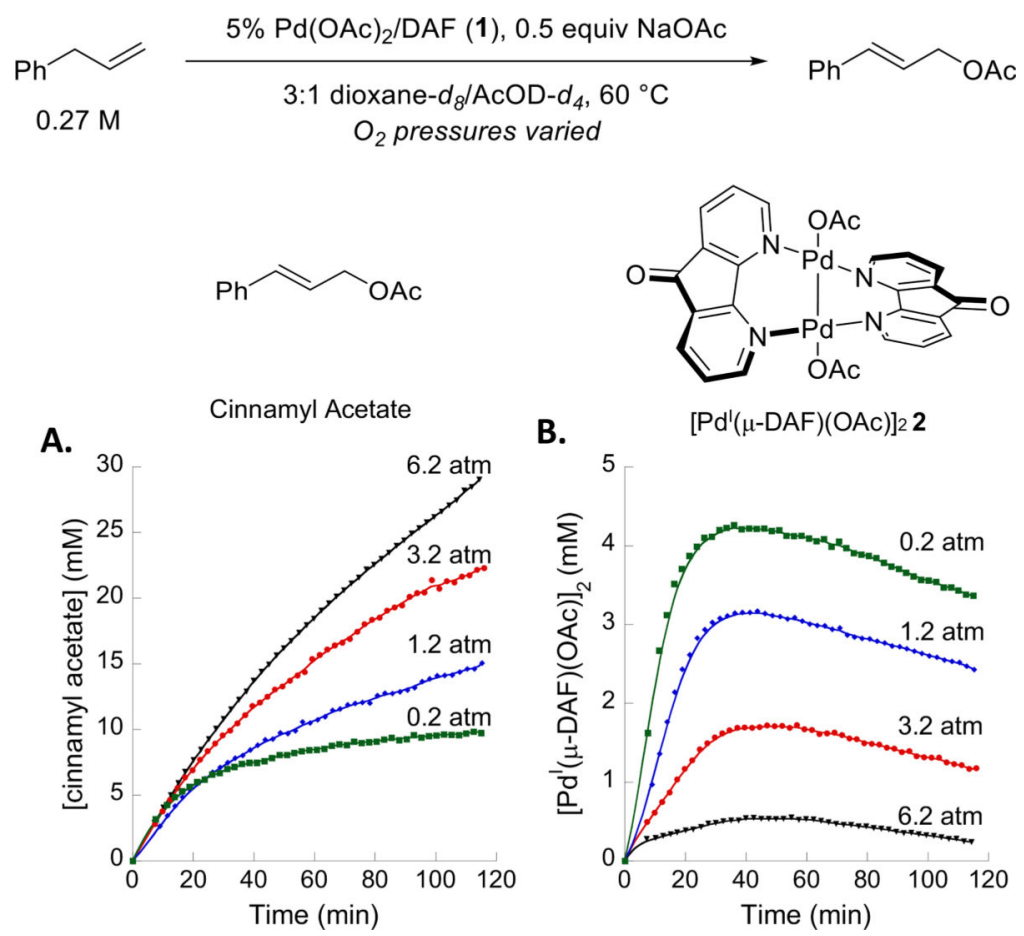

Figure 6.

Time courses with different initial pressures of $\mathrm{O}_{2}$ (static) monitored by NMR spectroscopy. Conditions: $[\mathrm{DAF}]=13.5 \mathrm{mM},\left[\mathrm{Pd}(\mathrm{OAc})_{2}\right]=13.5 \mathrm{mM}$, [allylbenzene $]=0.27 \mathrm{M},[\mathrm{NaOAc}]$ $=54 \mathrm{mM}, 60{ }^{\circ} \mathrm{C}$. (A) [cinnamyl acetate] over time at $p \mathrm{O}_{2}=0.2$ to $6.2 \mathrm{~atm}$. (B) $\left[\left[\mathrm{Pd}^{\mathrm{I}}(\mu \mathrm{DAF})\right.\right.$ $\left.(\mathrm{OAc})]_{2}\right]$ over time at $p \mathrm{O}_{2}=0.2$ to $6.2 \mathrm{~atm}$. Lines reflect a smooth fit to the data to guide the eye. 

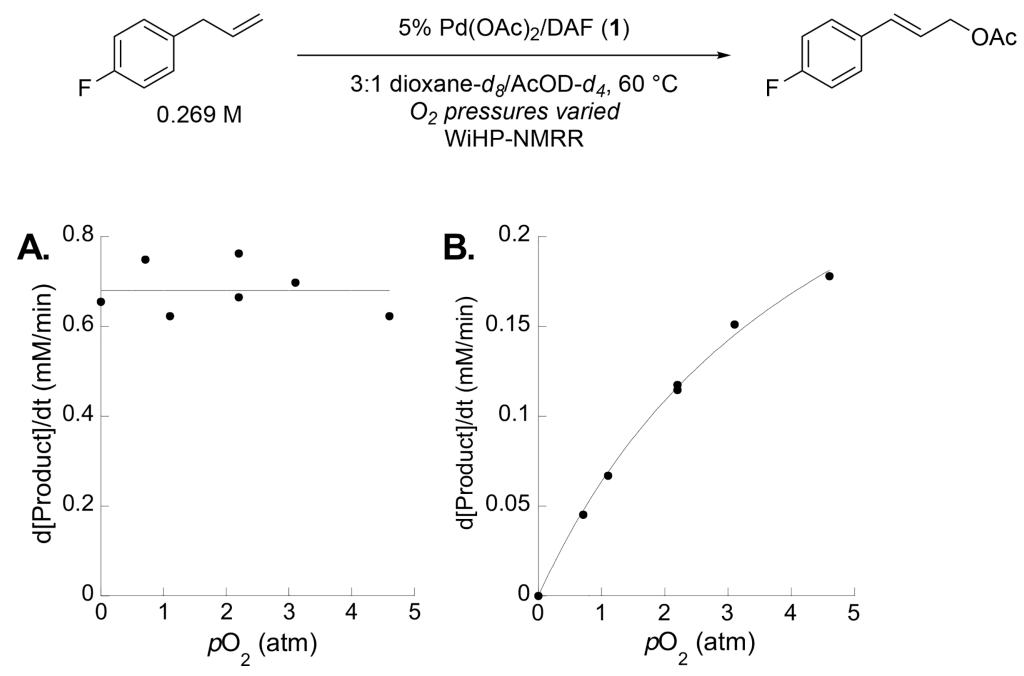

Figure 7.

Dependence of the rate of allylic acetoxylation on $\mathrm{pO}_{2}$ (dynamic) during (A) burst and (B) post-burst phase of the reaction. Conditions: $\left[\mathrm{DAF} / \mathrm{Pd}^{\mathrm{II}}(\mathrm{OAc})_{2}\right]=13.5 \mathrm{mM}$, [4-

fluoroallylbenzene] $=0.27 \mathrm{M}, 0-4.6$ atm $p \mathrm{O}_{2}$ using $9 \% \mathrm{O}_{2}$ in $\mathrm{N}_{2}, 60{ }^{\circ} \mathrm{C} ; \mathrm{NaOAc}$ was not used in order to prevent clogging of the gas inlet capillary. $\mathrm{ds}=0, \mathrm{~ns}=2, \mathrm{~d} 1=4 \mathrm{~s}$, circulation delay between scans $=0.5 \mathrm{~s}, \mathrm{aq}=0.3 \mathrm{~s}$. The line in (B) reflects a smooth fit to the data to guide the eye. 

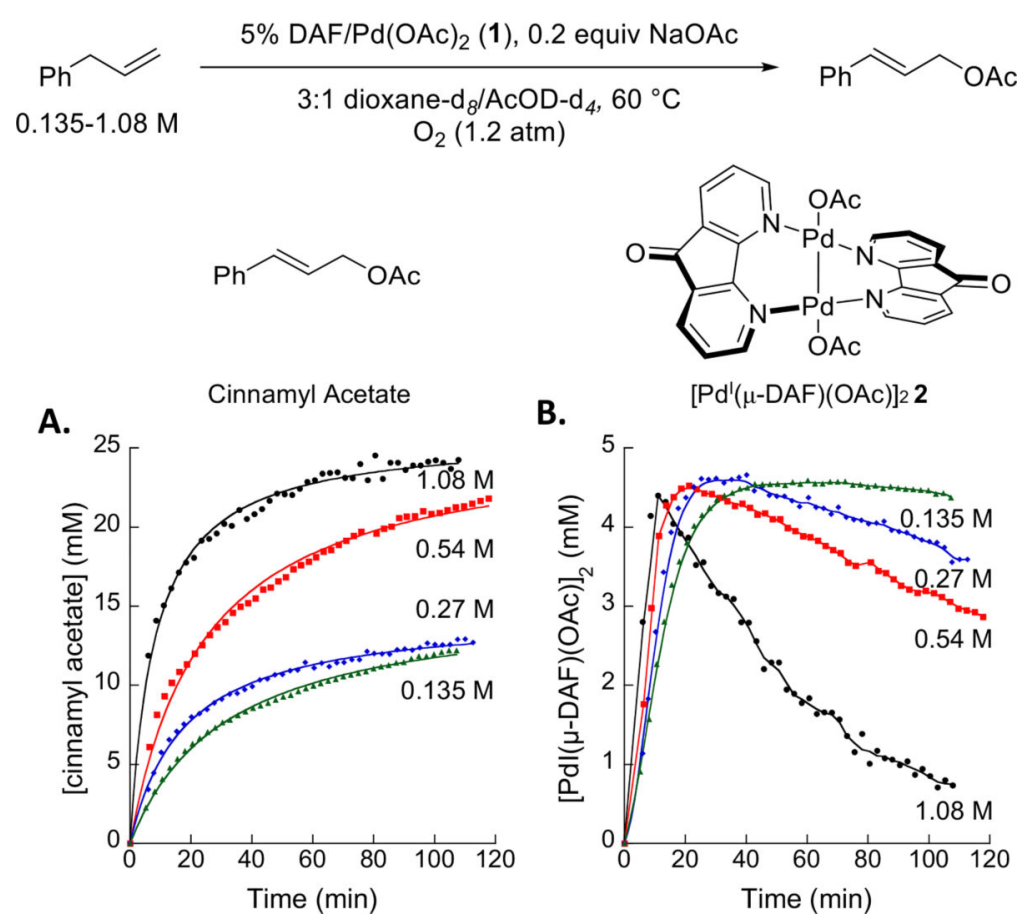

Figure 8.

Time courses with different concentrations of allylbenzene monitored by NMR spectroscopy under static $\mathrm{O}_{2}$ pressure. Conditions: $[\mathrm{DAF}]=13.5 \mathrm{mM},\left[\mathrm{Pd}(\mathrm{OAc})_{2}\right]=13.5 \mathrm{mM}$,

[allylbenzene] $=0.135-1.08 \mathrm{M},[\mathrm{NaOAc}]=54 \mathrm{mM}, 60^{\circ} \mathrm{C}, 1.2 \mathrm{~atm} \mathrm{O} \mathrm{O}_{2}$ (static). (A)

[cinnamyl acetate $]$ over time. (B) $\left[\left[\mathrm{Pd}^{\mathrm{I}}(\mu-\mathrm{DAF})(\mathrm{OAc})\right]_{2}\right]$ over time. Lines reflect a smooth fit to the data to guide the eye. 

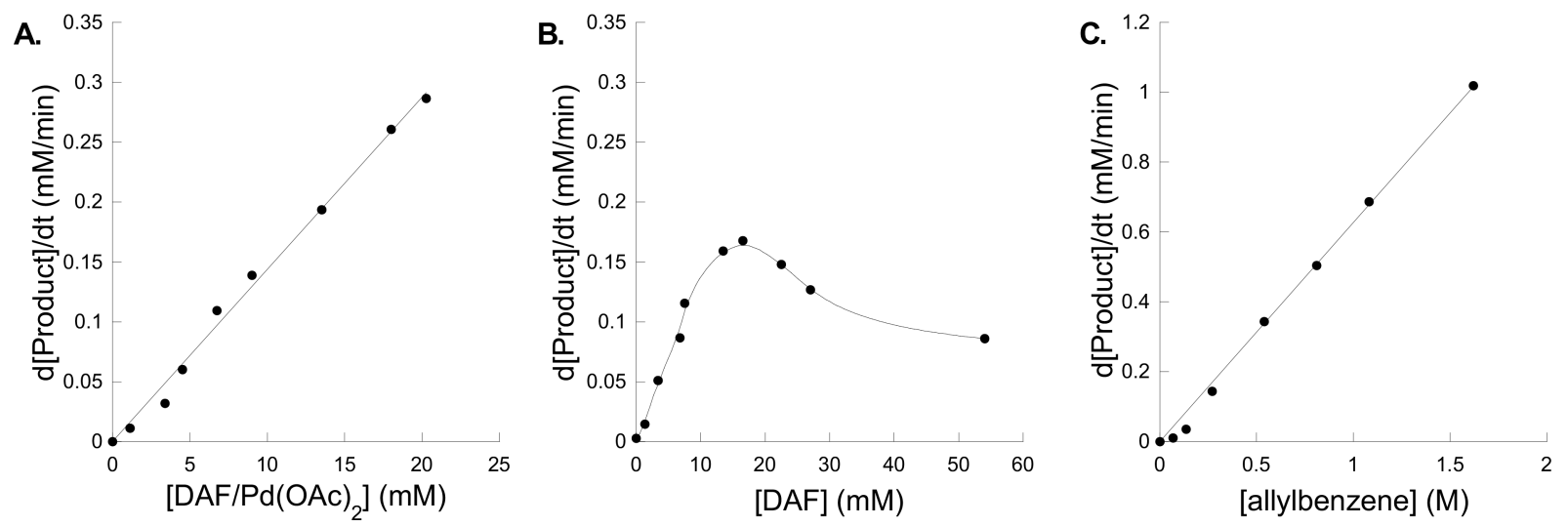

Figure 9.

Kinetic dependencies of reaction components for the burst phase. All experiments were performed at $40{ }^{\circ} \mathrm{C}$ in an orbital mixer with $1 \mathrm{~atm}$ of $\mathrm{O}_{2}$ and $54 \mathrm{mM} \mathrm{NaOAc}$. (A) [DAF] $=$ $\left[\mathrm{Pd}(\mathrm{OAc})_{2}\right]=0-18 \mathrm{mM}$, [allylbenzene $]=0.27 \mathrm{M}$. (B) $[\mathrm{DAF}]=0-54 \mathrm{mM},\left[\mathrm{Pd}(\mathrm{OAc})_{2}\right]=$ $13.5 \mathrm{mM}$, [allylbenzene] $=0.27 \mathrm{M}$. $(\mathrm{C})\left[\mathrm{DAF} / \mathrm{Pd}^{\mathrm{II}}(\mathrm{OAc})_{2}\right]=13.5 \mathrm{mM}$, [allylbenzene $]=$ 0.14-1.8 M. Average of multiple runs. Error within 10\%. The line in (B) reflects a smooth fit to the data to guide the eye. 

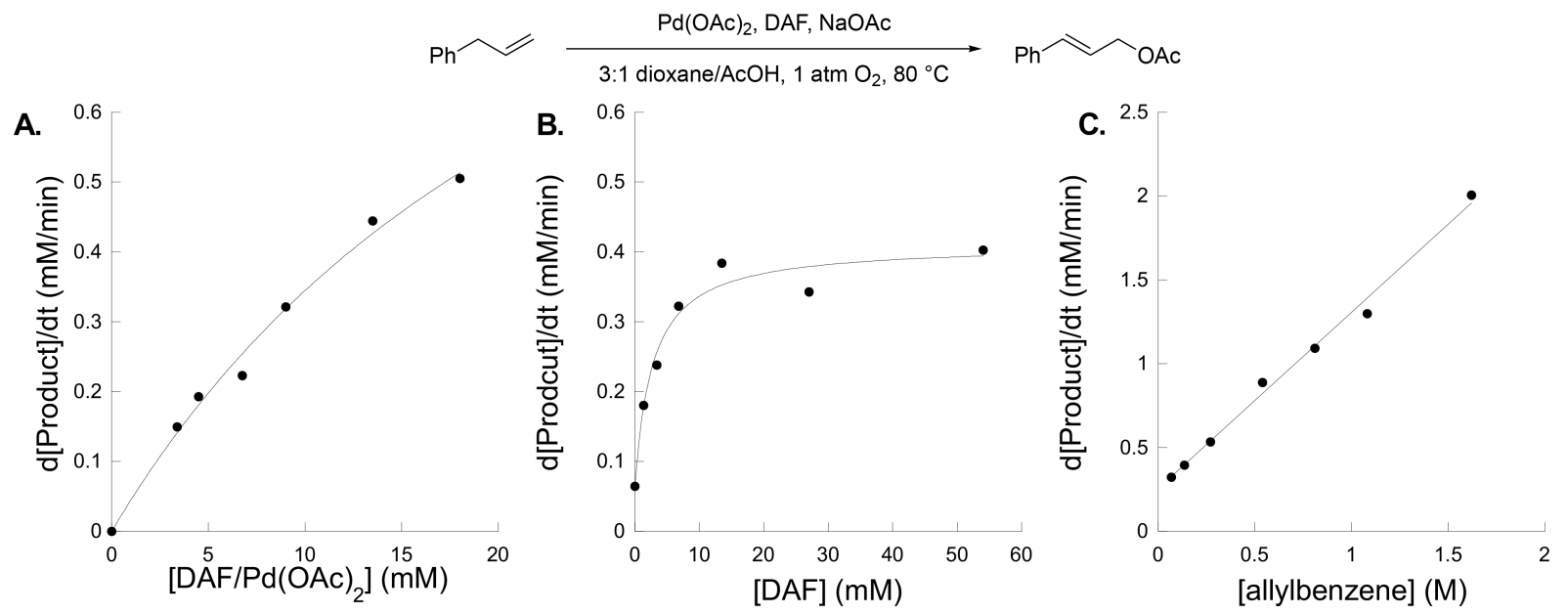

Figure 10.

Kinetic dependencies of reaction components after the burst phases of the reaction. All experiments were performed at $80^{\circ} \mathrm{C}$ in an orbital mixer with 1 atm of $\mathrm{O}_{2}$ and $54 \mathrm{mM}$ NaOAc. (A) $\left[\mathrm{DAF} / \mathrm{Pd}^{\mathrm{II}}(\mathrm{OAc})_{2}\right]=0-18 \mathrm{mM}$, [allylbenzene $]=0.27 \mathrm{M}$. (B) $[\mathrm{DAF}]=0-54$ $\mathrm{mM},\left[\mathrm{Pd}(\mathrm{OAc})_{2}\right]=13.5 \mathrm{mM}$, [allylbenzene $]=0.27 \mathrm{M}$. $(\mathrm{C})\left[\mathrm{DAF} / \mathrm{Pd}^{\mathrm{II}}(\mathrm{OAc})_{2}\right]=13.5 \mathrm{mM}$, [allylbenzene] $=0.14-1.8 \mathrm{M}$. Average of multiple runs. Error within $10 \%$. The lines for (A) and (B) represents a hyperbolic fit to the data, i.e., rate $=c_{1} \cdot x /\left(c_{2}+c_{3} \cdot x\right)$, with a non-zero intercept for (B). 

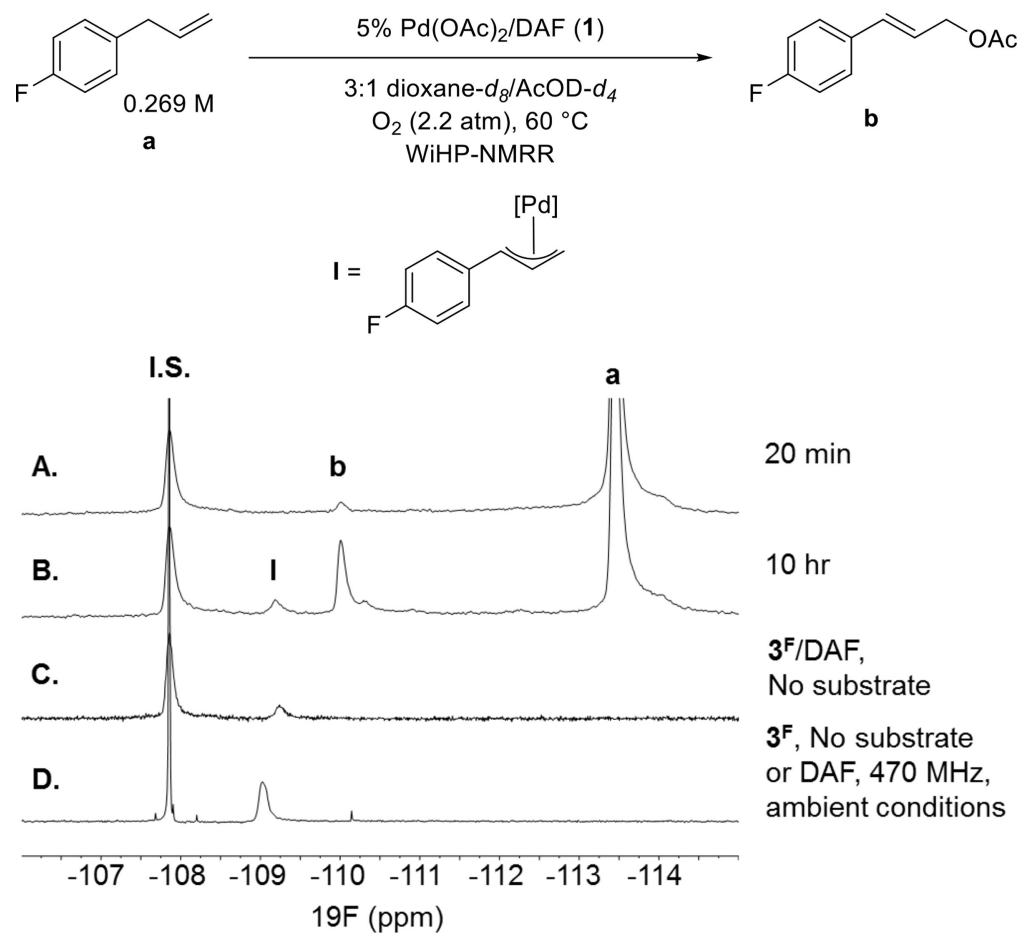

Figure 11.

In situ detection of a $\pi$-cinnamyl-Pd ${ }^{\mathrm{II}}$ resting state during the acetoxylation of 4fluoroallylbenzene using the WiHP-NMRR. $\mathrm{Pd}(\mathrm{OAc})_{2}$ as precatalyst, (A) 20 min and (B) 10 $\mathrm{h}$ after reaction initiation, $\mathbf{3}^{\mathrm{F}} / \mathrm{DAF}$ without substrate $(\mathrm{C})$, and $\mathbf{3}^{\mathrm{F}}$ under ambient conditions without other reaction components (D). Conditions: $[\mathrm{Pd}]=13.5 \mathrm{mM},[\mathrm{DAF}]=13.5 \mathrm{mM}$ (except for the bottom spectrum, where [DAF] $=0$ ), 3-fluoroanisole internal standard. [I.S.] $=55.7 \mathrm{mM}, 3: 1$ dioxane:AcOD- $d_{4}$. 


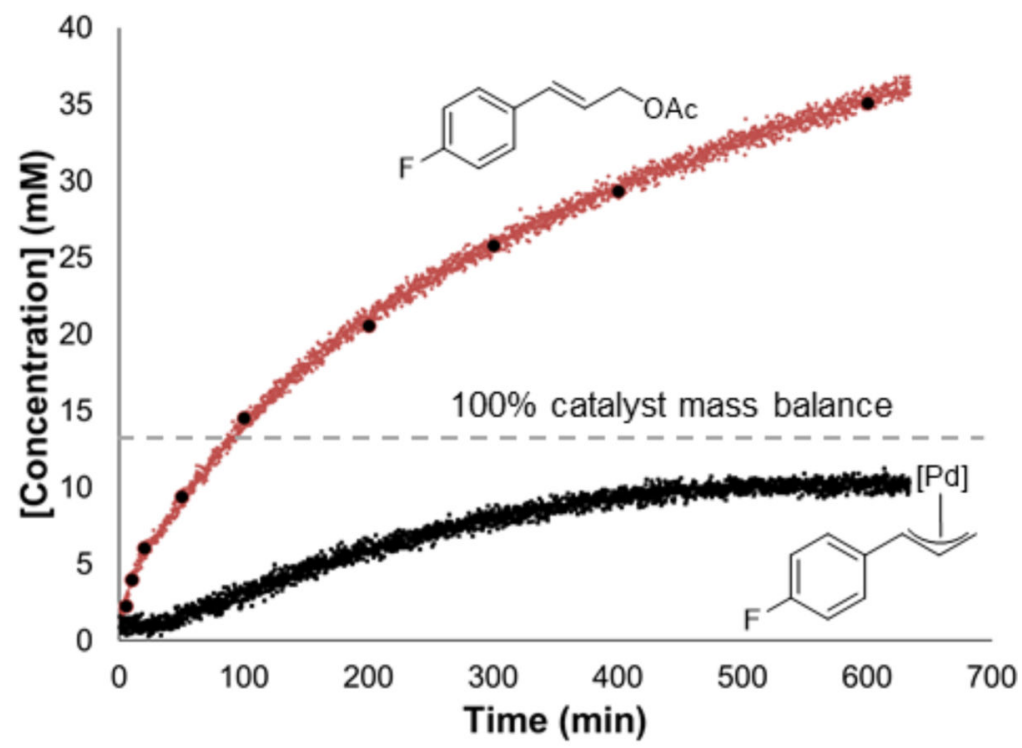

Figure 12.

Time course of DAF/Pd ${ }^{\mathrm{II}}(\mathrm{OAc})_{2}$-catalyzed allylic acetoxylation of 4-fluoroallylbenzene analyzed by ${ }^{19} \mathrm{~F}$ NMR spectroscopy using the WiHP-NMRR. See Figure 11 for reaction conditions. The superimposed points in the red data correspond to the representative NMR spectra depicted in the Supporting Information, Figure S12. 

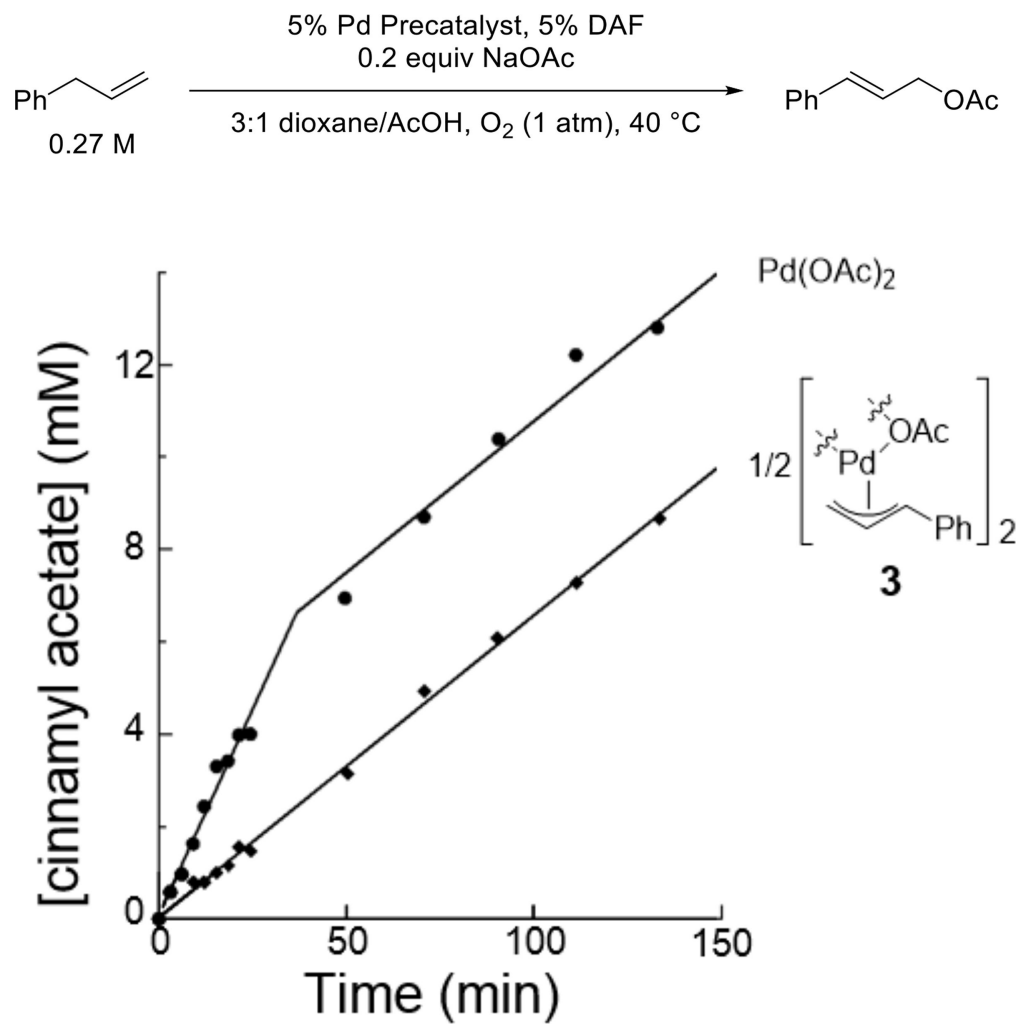

Figure 13.

Kinetic interrogation of the resting state. Pd precatalyst $=\mathrm{DAF} / \mathrm{Pd}{ }^{\mathrm{II}}(\mathrm{OAc})_{2} \mathbf{1}$ or $\left[\mathrm{Pd}^{\mathrm{II}}(\pi-\right.$ cinnamyl $)(\mathrm{OAc})]_{2} \mathbf{3}$. 


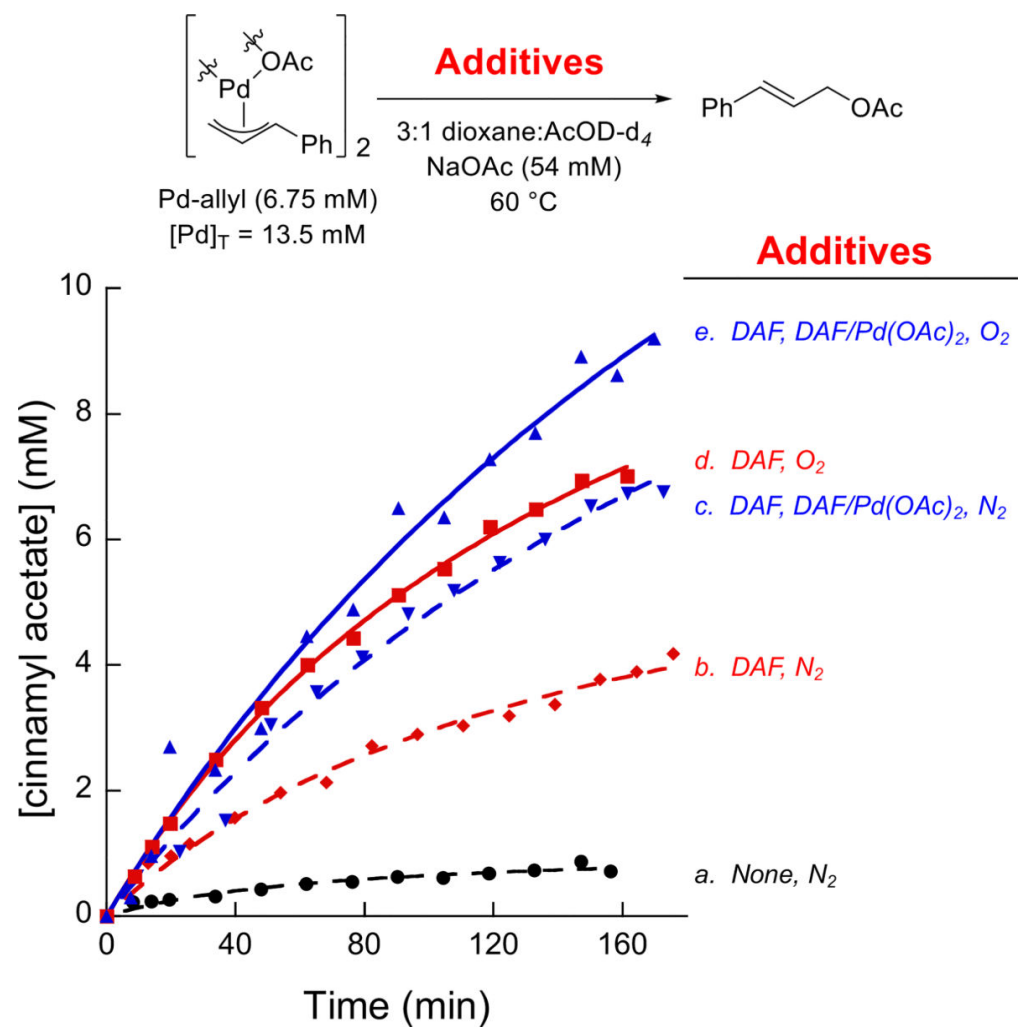

Figure 14.

Stoichiometric reductive elimination reactions of $\left[\mathrm{Pd}^{\mathrm{II}}(\pi \text {-cinnamyl })(\mathrm{OAc})\right]_{2}$. Conditions: $\left[\mathrm{Pd}^{\mathrm{II}}(\text { cinnamyl })(\mathrm{OAc})\right]_{2}=6.75 \mathrm{mM},[\mathrm{DAF}]=13.5 \mathrm{mM},\left[\mathrm{DAF} / \mathrm{Pd}(\mathrm{OAc})_{2}\right]=13.5 \mathrm{mM}$, $[\mathrm{NaOAc}]=54 \mathrm{mM}, 60^{\circ} \mathrm{C}, 3: 1$ dioxane:AcOD- $d_{4}, \mathrm{~N}_{2}$ or $\mathrm{O}_{2}$. The lines reflect smooth fits to the data to guide the eye. 


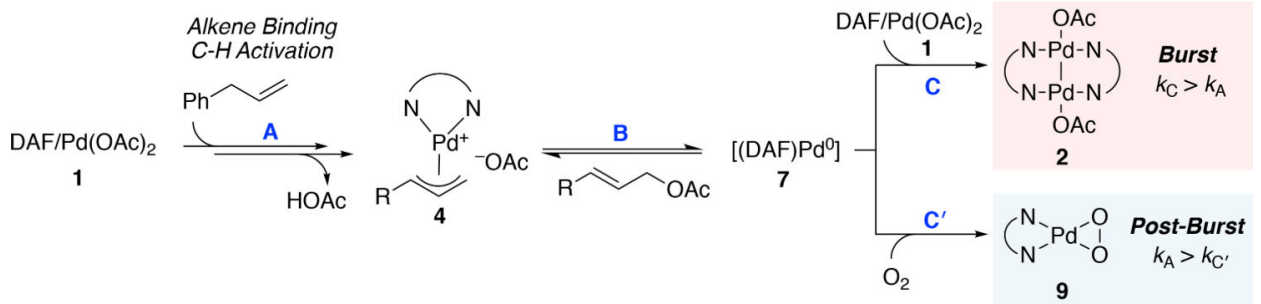

Figure 15.

Reaction scheme depicting trapping of $\mathrm{Pd}^{0}$ by $\mathrm{Pd}^{\mathrm{II}}(\mathbf{1})$ or by $\mathrm{O}_{2}$ during the burst and postburst phases of the reaction, with concurrent changes in the rate determining step of the reaction. 

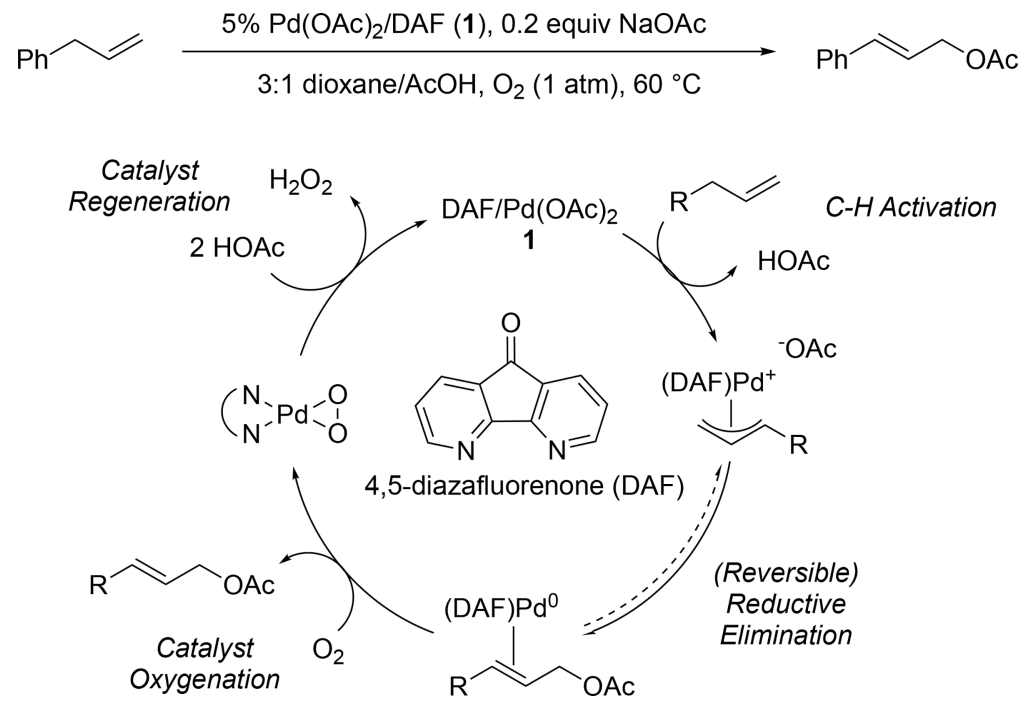

Scheme 1.

Proposed Mechanism for DAF-Promoted Pd-Catalyzed Aerobic Acetoxylation. 


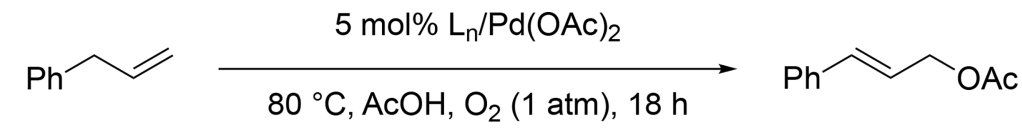

$\mathrm{L}_{\mathrm{n}}=$ None
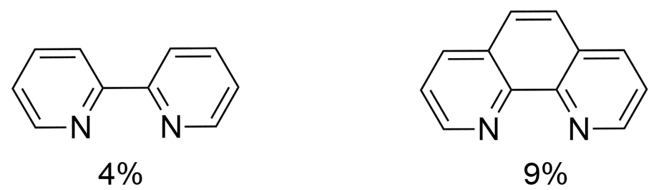

$4 \%$

$4 \%$

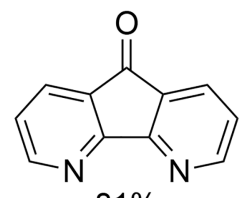

2<smiles>O=[W]1C=CC=CC=C1</smiles>

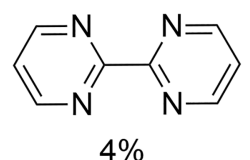

$81 \%$

Scheme 2.

DAF-Promoted Pd-Catalyzed Aerobic Allylic Acetoxylation of Alkenes. ${ }^{31}$ 

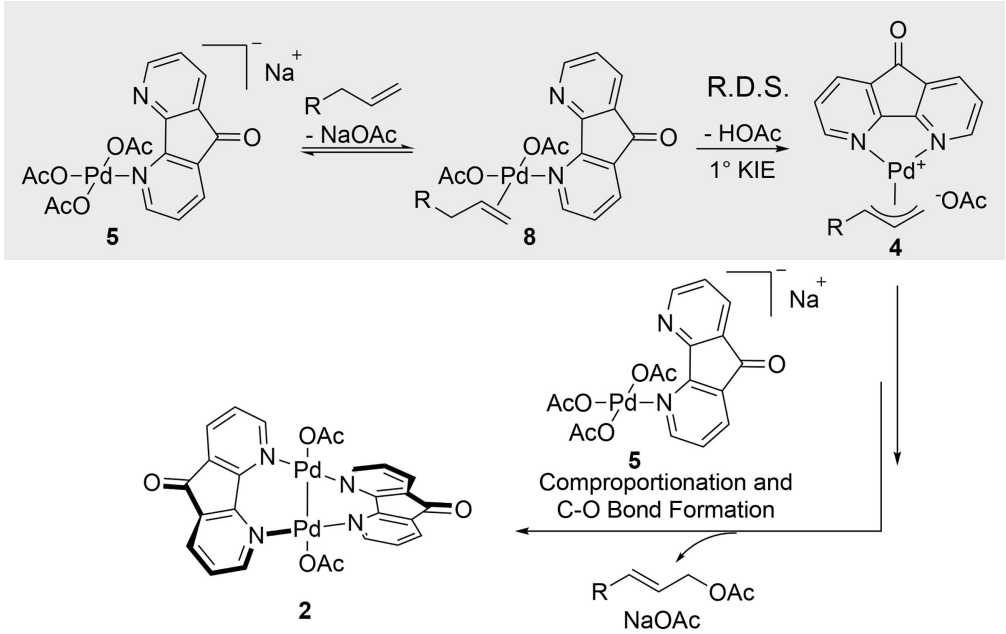

Scheme 3.

Mechanism of the Burst Phase of DAF/Pd ${ }^{\mathrm{II}}(\mathrm{OAc})_{2}$-Catalyzed Allylic Acetoxylation. 


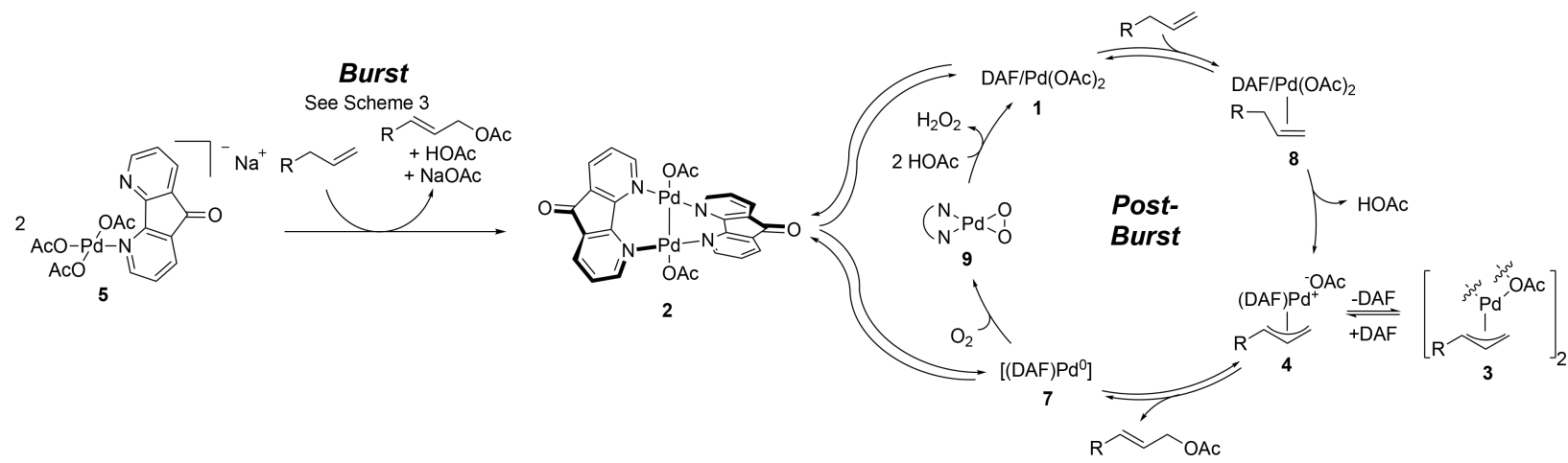

Scheme 4.

Full Mechanism of DAF/Pd ${ }^{\mathrm{II}}(\mathrm{OAc})_{2}$-Catalyzed Allylic Acetoxylation, Including the Burst and Post-Burst Phases of the Reaction. 
Table 1.

Kinetic Isotope Effects Obtained via Independent Rate Measurements with 6/6- $d_{2}$-Labeled Substrates and via Intramolecular Competition Using the 6- $d_{1}$-Labeled Substrate.

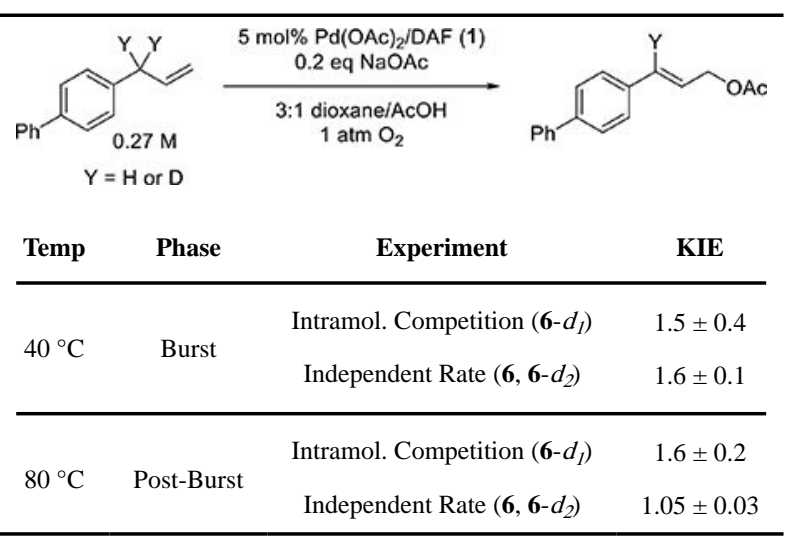


Table 2.

Summary of the Mechanistic Observations for the Burst and Post-Burst Regimes.

\begin{tabular}{ccc}
\hline & Burst & Post-Burst \\
\hline Primary Allylic C-H KIE & Yes & No \\
$p \mathrm{O}_{2}$ Dependence & No & Yes \\
DAF Speciation & DAF ligated to Pd ${ }^{\mathrm{II}}$ or $\mathrm{Pd}^{\mathrm{I}}$ & Appearance of free DAF \\
Catalyst Evolution & $\mathrm{DAF} / \mathrm{Pd}^{\mathrm{II}} \rightarrow \mathrm{Pd}^{\mathrm{I}}$ dimer & $\mathrm{Pd}^{\mathrm{I}}$ dimer $\rightarrow \pi$-allyl-Pd $\mathrm{Pd}^{\mathrm{II}}$ species \\
Turnover-Limiting Step & $\mathrm{C}-\mathrm{H}$ activation & $\mathrm{Pd}^{0}$ oxidation by $\mathrm{O}_{2}$ \\
\hline
\end{tabular}

oxidation by $\mathrm{O}_{2}$ 